\title{
Review Article \\ ROS, Cell Senescence, and Novel Molecular Mechanisms in Aging and Age-Related Diseases
}

\author{
Pierpaola Davalli, ${ }^{1}$ Tijana Mitic, ${ }^{2}$ Andrea Caporali, ${ }^{3}$ \\ Angela Lauriola, ${ }^{1}$ and Domenico D'Arca ${ }^{1,4}$ \\ ${ }^{1}$ Department of Biomedical, Metabolic and Neural Sciences, University of Modena \& Reggio Emilia, 41125 Modena, Italy \\ ${ }^{2}$ Bristol Heart Institute, University of Bristol, Bristol BS2 8HW, UK \\ ${ }^{3}$ University/BHF Centre for Cardiovascular Science, The Queen's Medical Research Institute, 47 Little France Crescent, \\ Edinburgh EH16-4TJ, UK \\ ${ }^{4}$ Istituto Nazionale di Biostrutture e Biosistemi, 00136 Roma, Italy
}

Correspondence should be addressed to Domenico D’Arca; domenico.darca@unimore.it

Received 16 December 2015; Revised 2 April 2016; Accepted 6 April 2016

Academic Editor: Michael Courtney

Copyright (C) 2016 Pierpaola Davalli et al. This is an open access article distributed under the Creative Commons Attribution License, which permits unrestricted use, distribution, and reproduction in any medium, provided the original work is properly cited.

\begin{abstract}
The aging process worsens the human body functions at multiple levels, thus causing its gradual decrease to resist stress, damage, and disease. Besides changes in gene expression and metabolic control, the aging rate has been associated with the production of high levels of Reactive Oxygen Species (ROS) and/or Reactive Nitrosative Species (RNS). Specific increases of ROS level have been demonstrated as potentially critical for induction and maintenance of cell senescence process. Causal connection between ROS, aging, age-related pathologies, and cell senescence is studied intensely. Senescent cells have been proposed as a target for interventions to delay the aging and its related diseases or to improve the diseases treatment. Therapeutic interventions towards senescent cells might allow restoring the health and curing the diseases that share basal processes, rather than curing each disease in separate and symptomatic way. Here, we review observations on ROS ability of inducing cell senescence through novel mechanisms that underpin aging processes. Particular emphasis is addressed to the novel mechanisms of ROS involvement in epigenetic regulation of cell senescence and aging, with the aim to individuate specific pathways, which might promote healthy lifespan and improve aging.
\end{abstract}

\section{Introduction}

The reduced rate of birth and mortality is the motive of the older population growth in western industrialized countries, where advanced age remains the fundamental risk factor for most chronic diseases and functional deficits. As an example, it is estimated that the individuals of age 65 and above in the USA will reach $20 \%$ by 2030 , while they constituted $12.4 \%$ in 2004 [1]. Human aging is developed from such an accumulation of physical, environmental, and social factors that the definition of the molecular mechanisms that trigger the aging means a difficult task. Some theories associate various factors with aging rate, as changes of metabolic control [2] and gene expression patterns [3] and production of high levels of Reactive Oxygen Species (ROS) [4]. Low ROS level has been, instead, associated with lengthening of organismal lifespan [5]. Current studies aim at deepening how cell senescence process, so far experimented in vitro, may be extended to in vivo studies. Increasing evidence for causal role of cell senescence has been demonstrated in age-related dysfunctions and pathologies [6]. Senescent cells proliferate in aging, as a stress response primed by a number of "counting mechanisms," like telomeres shortening, DNA damage accumulation, abnormal oncogenes activities, metabolic alterations, and excessive ROS generation [7]. These mechanisms cause cell proliferating arrest and generate features, as constitutive production of high ROS levels, critical for the senescent phenotype maintenance. Despite increasing modestly, as a number, the senescent cells are implicated in age-related diseases promotion, through the restriction of the regenerative pool of the tissue 
stem cells [8]. Some observations indicate that senescent cells do not necessarily induce mechanisms that promote aging and can be efficiently removed from the human body [9]. The general consensus on cellular damage accumulation, as aging initial event, suggests that cell senescence process is a major question regarding biological and clinical aging aspects [10].

Here, we review evidences on novel molecular mechanisms of the "ROS signaling" during aging and related pathologies, because they suggest a way of promoting healthy lifespan and improve human aging.

\section{ROS Physioma Homeostasis}

The ROS physioma is a family of highly reactive molecules which includes free oxygen radicals, like superoxide anion $\left(\mathrm{O}_{2}{ }^{\cdot-}\right)$, hydroxyl radical $\left(\mathrm{OH}^{\bullet}\right)$, and nonradical oxygen derivatives, like the stable hydrogen peroxide $\left(\mathrm{H}_{2} \mathrm{O}_{2}\right)$. The superoxide radicals react to form other ROS, namely, hydrogen peroxides and hydroxyl radicals, and interconvert with reactive nitrogen species (RNS), which generate effects similar to ROS [11]. The inefficient electron transfer in mitochondrial respiratory chain is believed to be a main ROS source, among diverse possible enzymatic and nonenzymatic sources [12]. Increased expression of catalase and peroxiredoxin1 molecules are considered as OS markers. The family comprises seven transmembrane members, namely, Noxl5 [13-15] and Duoxl-2 [16]. ROS are generated by oxygen metabolism (i.e., cellular respiration) in all the cells that utilize oxygen, as inevitable consequence of aerobic life, and may derive from exogenous metals, recycling of redox compounds, radiation, chemotherapeutic agents, carcinogens (estrogenic molecules), and other dietary and environmental means. Generally, the ROS increasing levels cause nonlinear cellular responses [17]. A fine balance between oxidant-antioxidant mechanisms leads to continuous modulation of ROS production, location, and inactivation, in both physiological and pathological conditions. Endogenous antioxidants, like the enzymes of catalase family, glutathione group, thioredoxin-related group, and superoxide dismutase [18], together with exogenous antioxidant as reduced glutathione [19], carotenoids, and vitamins C and E, constitute the indispensable ROS detoxifying system. Nevertheless, imbalance of redox homeostasis may occur, usually in favor of oxidants, so that ROS shift from physiological to potentially harmful levels, named oxidative and nitrosative stress (OS/NS). Increased expression of catalase and peroxiredoxin 1 molecules are considered as OS markers [20-22].

2.1. ROS Measurement Techniques. ROS are so highly variable and freely diffusible molecules that the detection of ROS and antioxidants, to obtain a picture of the cellular redox status, still represents a challenge. We stress some specific points and sensitive methods that are subjected to continuous improvement. Probes and antibodies have been developed to recognize oxidative damage by ROS/RNS [23-25]. The tools allow revealing antioxidant enzymes [26] and a variety of oxidative products, as lipid peroxidation products, protein carbonyls [27], oxidized DNA products [28], and nitrotyrosine [29]. Combinations of diverse approaches will prove essential for understanding ROS involvement in aging and age-related diseases [30]. An innovative method simultaneously assesses glutathione, hydrogen peroxide, and superoxide levels in a single cell, together with cell viability alterations, thus allowing for defining both oxidant-antioxidant balance and cell death, after the administration of a specific stimulus [31]. A wide range of pathways and molecular mechanisms that involve ROS suggests determining the redox state of thiols in ROS targets, which compose the "cellular oxidative interface" $[32,33]$. ROS oxidize specific protein residues of cysteine into sulfenic acid, reversibly. This molecule functions as OS/NS sensor within enzymes and transcriptional regulatory factors and may allow priming the routes of the versatile ROS action [34-36].

2.2. ROS Functions. The increasing comprehension of mechanisms, underlying the oxidant milieu of the cell, shows ROS as signaling molecules, besides metabolic byproducts. They act in a myriad of pathways and networks, mediated by hormones, which ranges from protein phosphorylation to transport systems, for example. ROS do not influence single steps of multistep processes; rather, they influence all the steps at the same time, by reacting with several compounds and taking part in several redox reactions. Depending on ROS concentration, molecular species, and subcellular localization, cell components and signaling pathways are affected positively or negatively. ROS levels are believed to be a "redox biology" that regulates physiological functions, including signal transduction, gene expression, and proliferation. "Redox biology," rather than OS, has been proposed to underlie both physiological and pathological events [37]. Data in the literature on slow and constant ROS increases have to be integrated with data on fast and stepwise ROS increases, typical of signaling events, which deliver messages among cellular compartments. Questions related to ROS dynamics and specificity, as the effects of their waves of concentration on networks with other signaling pathways, are investigated in single cells and across different cells. Proteins are the major target of ROS/RNS signaling and undergo reversible or irreversible modifications of their functions, which result in cell death, growth arrest, and transformation. The modulation of the reversible oxidation of redox-sensitive proteins plays basic roles in sensing and transducing the oxygen signal. Receptor-dependent or nondependent tyrosine kinases, AMP-activated protein kinases, adaptor protein p66SHC, and transcription factors as FOXO (forkhead homeobox type O), Nrf2 (nuclear factor E2-related factor 2), p53 (tumor suppressor 53), NF$\kappa \mathrm{B}$ (nuclear factor kappa B), AP-1 (activator protein-1), HIF-1a (hypoxia inducible factor-1a), PPAR $\gamma$ (peroxisome proliferator-activated receptor gamma), and $\beta$-catenin/Wnt signaling are listed in Table 1 [38-81]. ROS mediate in vitro response towards intra- and extracellular conditions, such as growth factors, cytokines, nutrients deprivation, and hypoxia, which regulate cell proliferation, differentiation, and apoptosis, besides being important cancer hallmarks [82]. Intrinsic and extrinsic factors control ROS regulation on cellular selfrenewal, quiescence, senescence, and apoptosis, during the in vivo tissues homeostasis and repair [83] and in ROS 
TABLE 1: Selected ROS sensitive proteins that are involved in cell signaling transduction mechanism. Indicative examples of possible effects and processes they promote after being directly and/or indirectly modified by ROS (the references are indicated inside the square brackets).

\begin{tabular}{|c|c|c|}
\hline $\begin{array}{l}\text { ROS sensitive proteins: } \\
\text { oxidative interface }\end{array}$ & $\begin{array}{l}\text { (1) Effects of ROS sensitive proteins after being } \\
\text { redox modified }\end{array}$ & $\begin{array}{l}\text { (2) Physiopathological processes in which ROS } \\
\text { sensitive proteins are involved }\end{array}$ \\
\hline \multicolumn{3}{|l|}{ Protein kinases } \\
\hline $\begin{array}{l}\text { Receptor/nonreceptor tyrosine } \\
\text { kinases } \\
\text { (Src, TRK, AKT, c-Abl, MAPK, } \\
\text { CaMKII, PKG, ATM, and Ask1) }\end{array}$ & $\begin{array}{l}\text { (i) Interactions between kinases pathways }[38,39] \\
\text { (ii) Signal of ROS production feedback }[40]\end{array}$ & $\begin{array}{l}\text { Control of cell cycle progression [56] } \\
\text { Mitosis for anchorage-dependent cells [57] } \\
\text { Cellular homeostasis }[43,57]\end{array}$ \\
\hline $\begin{array}{l}\text { AMP-activated protein kinases } \\
\text { (AMPK) }\end{array}$ & (i) Regulation of cell ROS/redox balance $[41,42]$ & $\begin{array}{l}\text { Myocyte adaptation to energy requirement [42] } \\
\text { Adipocyte differentiation [58] } \\
\text { Lipid metabolism ("fatty liver") [59] } \\
\text { Hyperglycemic damage [60] } \\
\text { Cell fate (autophagy and apoptosis) [61] }\end{array}$ \\
\hline \multicolumn{3}{|l|}{ Adaptor proteins } \\
\hline p66Shc & (i) Signaling start in the aging process [43] & $\begin{array}{l}\text { Apoptosis [43]. Prolonged life span [43, 62] } \\
\text { Cardiovascular diseases and obesity [63] } \\
\text { Diabetic endothelial dysfunction [64] }\end{array}$ \\
\hline \multicolumn{3}{|l|}{ Nuclear receptors } \\
\hline $\operatorname{PPAR} \gamma$ & $\begin{array}{l}\text { (i) Redox sensor function [43] } \\
\text { (ii) Regulation of genes that modulate ROS } \\
\text { increases [44] }\end{array}$ & $\begin{array}{l}\text { Neurodegenerative diseases }[65,66] \\
\text { Lipid dysfunction (fatty liver) [59] }\end{array}$ \\
\hline \multicolumn{3}{|l|}{ Membrane receptors } \\
\hline Elements in Notchl pathway & $\begin{array}{l}\text { (i) Notch signaling modulation in association } \\
\text { with Wnt/beta-catenin signal [45] }\end{array}$ & $\begin{array}{l}\text { Cell fate control in vascular development [45] } \\
\text { Biological clocks in embryonic development [67] }\end{array}$ \\
\hline \multicolumn{3}{|l|}{ Transcription factor } \\
\hline p53 & $\begin{array}{l}\text { Modulation of cell redox balance } \\
\text { (prooxidant/antioxidant effects) [46-48] }\end{array}$ & $\begin{array}{l}\text { Cell fate signaling }[68] \\
\text { Autophagy and apoptosis }[61,69]\end{array}$ \\
\hline Nrf2 & Cell adaptation to ROS resistance $[49,50]$ & $\begin{array}{l}\text { Apoptosis [70] } \\
\text { Neurodegenerative diseases [71] } \\
\text { Cardiovascular diseases [72] }\end{array}$ \\
\hline FOXO3A & Cell coordination in response to OS [51] & $\begin{array}{l}\text { Metabolic adaptation to low nutrient intake [73] } \\
\text { Cancer development [73] } \\
\text { Diabetes [74] } \\
\text { Atherosclerotic cardiovascular disease [75] }\end{array}$ \\
\hline $\begin{array}{l}\text { Components in } \beta \text {-catenin/Wnt } \\
\text { pathway }\end{array}$ & $\begin{array}{l}\text { Regulation of Wnt signaling via nucleoredoxin } \\
\text { [76] }\end{array}$ & $\begin{array}{l}\text { Early embryonic development [76] } \\
\text { Vascular development [45] }\end{array}$ \\
\hline HIF-1a & $\begin{array}{l}\text { Cell adaption to oxygen tension modifications } \\
\text { [52] }\end{array}$ & $\begin{array}{l}\text { Cell proliferation; angiogenesis }[77] \\
\text { Cell transformation }[78,79]\end{array}$ \\
\hline $\begin{array}{l}\text { Components in JAK-STAT } \\
\text { pathway }\end{array}$ & $\begin{array}{l}\text { (i) Cell adaption to OS [53] } \\
\text { (ii) Mediation of ROS mitogenic effect [53] }\end{array}$ & $\begin{array}{l}\text { Stress response gene expression [51] } \\
\text { Systemic/pulmonary hypertension [80] }\end{array}$ \\
\hline $\mathrm{NF}-\kappa \mathrm{B}$ & $\begin{array}{l}\text { Regulation of redox-sensitive gene expression } \\
{[54,55]}\end{array}$ & $\begin{array}{l}\text { Rheumatoid arthritis, dyslipidemia, } \\
\text { atherosclerosis, and insulin resistance [81] }\end{array}$ \\
\hline
\end{tabular}

induction of stem cells proliferation and differentiation. ROS act as a rheostat, which senses and translates environmental cues in stem cells response, thus balancing cellular output (function) with cellular input (nutrients, cytokines). The stem cells may undergo exhaustion depending on ROS levels [84]. Mitochondrial ROS may activate an adaptive response (mitohormesis), which, as defensive mechanism, promotes health to extend the lifespan through diseases prevention and delay $[5,85]$. ROS is integral in the development of physiopathologic events like mitochondrial death signaling [86] and autophagy [87], besides inflammation and infection $[55,88]$, in which they impart immunological changes. High ROS levels are generated by professional cells (lymphocytes, granulocytes, and phagocytes) in defense against microbes $[89,90]$. Differently, any event which contributes to chronic OS or NS, through its increased generation or defective detoxification, dysregulates signaling networks, alters lipids and protein and nucleic acids, and activates mechanisms to face the changes. ROS overproduction hampers damaged nuclear and mitochondrial DNA repair, at multiple steps, contributing to cell genomic instability [91]. ROS are recognized as key modulators in processes that accumulate oxidized molecules chronically, as diabetes, cardiovascular diseases, atherosclerosis, hypertension, ischemia, reperfusion injury, neurodegeneration, and rheumatoid arthritis [17]. Also, ROS participate in cancer development through their 
effects on cellular proliferation, mutagenesis, and apoptosis inhibition [56]. The cross talk between ROS, p53, and NF- $\kappa$ B plays crucial roles in tumorigenesis. OS is allied with energy metabolism to stimulate the growth of cells transformed by oncogenes or tumor suppressors [92-94]. The deregulated ROS productions in cancer cells and the consequent constitutive OS may cause the cellular invasive phenotype [57].

Although ROS functions remain difficult to investigate, multiple pharmacological investigations are in progress to maintain ROS homeostasis through both OS decrease and antioxidant defense increase $[95,96]$.

\section{ROS in Aging and Age-Related Diseases}

Poor knowledge of basic processes in aging interferes with interventions to prevent or delay age-related pathologies, like diabetes, cardiovascular disorders, neurodegenerative disorders, and cancer, which, consequently, impact human independence, general wellbeing, and morbidity [97-99]. Recently, interest has been focused on stem cells, because their decline impairs tissues homeostasis maintenance, leading to the organism weakening and the age-related diseases [84]. Aging mechanisms have been collected into two classes. The first class presents aging as genetically programmed by developmental processes, like the cell senescence, the neuroendocrine alterations, and the immunological alterations. The second class presents aging caused by random damage, that is, accumulation of somatic mutations and OS. The separation between the classes is no longer considered clear, because pathways involved in aging often share features with specific diseases [100]. The genetic heredity contributes no more than 3\% to aging, while epigenetic processes and posttranslational processes imprint a significantly different aging rate among diverse populations, as well as among diverse anatomical sites of a single organism. In the onset of aging, telomere erosion, OS, and cell senescence are crucial events that originate from the disorganized homeostasis of cell metabolism. For example, mitochondria-nucleus interplay [101] and alterations of mitochondrial homeostasis drive age-dependent modifications [102, 103]. Ineffective ROS control on mitochondrial supercomplexes causes ROS signaling alteration, thus mediating cell stress responses towards age-dependent damage [104]. A progressive ROS scavengers decrease shifts aged cells towards a prooxidant status $[105,106]$. In parallel, all the suggested methods to prolong lifespan, as caloric restriction and increased activity of SIRT1, share the OS reduction effect [107]. It is known that chronic muscular exercise protects older persons from damage caused by OS and reinforces their defenses against it. On the other hand, acute exercise increases ROS production and damage from ROS [108]. High levels of mitochondrial ROS contribute to aging of genetically modified animals, in a mechanistic way. Superoxide dismutase-deficient animals, SOD1- [109] and SOD3-deficient animals [110], and p66SHCdeficient animals show mitochondrial dysfunctions that generate oxidative damage and related phenotypes, resembling premature aging features. Similarly, mice that overexpress mitochondrial catalase counteract oxidative damage and live longer. The incidence of age-related diseases and pathologies in animal models, after they have been submitted to disparate patterns, suggests that OS influences old age aspects significantly [111]. The observations have been extended to humans, even if rate and distribution of mitochondrial mutations may deviate from animals. The conclusions regarding OS effect on aging in animals from mitochondrial genetic manipulations are still conflicting. SOD+/- mice have reduced ROS detoxifying ability and high ROS level, while they exhibit a quite normal lifespan. OS effect on worms' lifespan depends on where ROS are produced: high mitochondrial or cytoplasmic levels are associated with increased and decreased lifespan, respectively $[109,112]$. It remains to define whether models' longevity is entirely associated with response to OS, because their lifespan is not affected by modulation of the antioxidant defense. The complex genetic manipulation of the models might weaken their support to the "OS theory of aging." Interventions to ROS lowering, by both scavenging free radicals and enhancing antioxidant defenses, are widely proposed as an antiaging strategy. However, positive association between supplementation with pharmacological or natural compounds and health beneficial effects has not been evidenced. Some antioxidants may be eventually useless or even harmful $[113,114]$. Moreover, a number of ROS-independent mitochondrial dysfunctions appear so involved in aging that doubts arise that OS is the most concrete contributor to fuel aging [115]. Based on the consideration that mitochondrial DNA (mtDNA) is a precise marker to detect total mitochondrial OS, methods have been developed to measure mtDNA replication defects and the oxidative damage level, simultaneously. The errors in mtDNA replication and repair, which accumulate through clonal expansion in advanced age, result in a major source of mtDNA mutations, rather than the errors acquired through ROS-dependent vicious cycles [116]. Summarizing, ROS are involved in elderly lesions that concern (i) DNA insufficiency, which is partly responsible for premature aging and apoptosis [117]; (ii) RNA involvement in the onset of chronic-degenerative diseases [118]; (iii) nuclear lamins that participate in cell proliferation and longevity [119]. The variations of speed and quality in the aging of each organism may reflect the peculiar alterations that have been accumulated in DNA, proteins, and lipids [120], following the organism exposition to chronic stressors. Low ROS levels improve the defense mechanisms by inducing adaptive responses, which contributes to stress resistance and longevity, while high ROS levels induce insufficient adaptive responses, which may contribute to aging onset and progression [121].

In conclusion, accumulated mutations, decreased mitochondrial energy metabolism, and increased OS may significantly contribute to the human aging and the related diseases.

\section{ROS-Dependent Epigenetic Modifications}

Intra- and extracellular environments change hereditary characters at the epigenetic level, without altering genes sequence [122]. The interplay between modified histones, DNA methylation, regulator noncoding RNAs, and other reversible processes constitutes the epigenetic machinery that regulates genes transcription and expression [123]. The epigenetic modulation provides the essential and flexible interface 
between organism and environment, which is essential for all the cell functions. The extent to which epigenome has shaped, and might shape, human populations over generations is investigated by an International Human Epigenome Consortium (http://www.ihec-epigenomes.org/). Both long- and short-acting stimuli lead to epigenetic effects that result in 13 being long-term (heritable) or short-term (nonheritable), respectively. These features suggest epigenetic modifications as more attractive target for therapeutic interventions in humans than genetic modification, throughout the entire life [124]. ROS operate modifications on histone and DNA, by acting in interconnected epigenetic phases, during mitochondrial and nuclear DNA regulation $[125,126]$. A clinical example of ROS-dependent epigenetic modifications is demonstrated in "nonalcoholic fatty liver" disease. The pathology represents the most common cause of chronic liver disease in western countries and affects one-third of the population. Altered redox mechanisms mediate the link between increased accumulation of triglycerides in hepatocytes and epigenetic modifications that are recognized as crucial factors in the pathophysiology of this disease [127]. About the basic mechanisms of ROS action, Afanasev proposes that ROS might cause epigenetic activation and repression, by acting like nucleophilic compounds, which accelerate and decelerate hydrolysis and esterification reactions. The hypothesis suggests a ROS role different from free radicals, because the last molecules cause an irreversible damage of the compounds with which they react [128].

4.1. ROS-Induced DNA Methylation. Usually, condensed chromatin structure (heterochromatin) is associated with genes repression by hypomethylation processes, while open chromatin (eu-chromatin) is associated with genes activation by acetylation processes [129]. The epigenetic marking modulates the genes expression by altering the electrostatic nature and the protein binding affinity of chromatin. DNA methylation causes gene silencing through inhibiting the transcriptional activators access to the target binding sites, or through activating the methyl-binding protein domains. The last function interacts with histone deacetylases and promotes chromatin condensation into transcriptionally repressive conformations. Hypo- and hypermethylation stages occur consecutively, indicating how DNA methylation and the correlate mechanisms of DNA binding are complex. ROS-dependent modifications are related to DNA methylation and demethylation, directly or indirectly. The NF- $\kappa \mathrm{B}$ binding to DNA, which is methylation dependent, results in being altered in SOD $(\mathrm{Cu} / \mathrm{Zn})$-deficient mice. The observation associates ROS-dependent modifications with altered methylation processes, although indirectly, and suggests that modifications linked to altered redox mechanisms may fit into cell signaling pathways [130]. Also, the oxidation of deoxy-guanine of CpG nucleotides to 8 -hydroxy-2' -deoxyguanosine $(8-\mathrm{OHdG})$ is believed to be a surrogate marker of oxidative damage, in various human diseases [131]. The 8-OHdG adducts interfere with DNA restriction nucleases and DNA methyl transferases (DNMT), thus altering transcription factors binding to DNA and causing general DNA hypomethylation. In vitro [132] and in vivo [133] studies demonstrate that ROS induce general genome hypomethylation and specific DNA promoters hypomethylation, via the DNMT upregulation and the DNMT complexes generation. Moreover, recent studies show that a ROS-mediated pathway causes repression of the protein kinase $\mathrm{C}$ epsilon gene, through its promotor methylation. The events are important in heart hypoxia, in utero, which leads to heightened heart vulnerability to ischemic injury, later in people's life [134].

4.2. ROS and DNA Methylation in Aging and Age-Related Diseases. Starting from the observation that both defective genome and DNA repair processes promote phenotypes of premature aging, the "aging epigenetics" has been developed as emerging discipline, which concerns genes and processes impacting aging (Figure 1) [135]. ROS effects on epigenetic mechanisms have been discussed as cause and consequence of aging and age-related DNA modifications [128]. Recent studies demonstrate that global DNA hypomethylation is deeply included in aging gene expression [136], and, at the same time, cancer is the age-related disease that shows the most significant effects of ROS-dependent DNA methylation [137]. Tumor progression is induced by general hypomethylation of the DNA and hypermethylation of tumor suppressor genes that lead to aberrant genes expression [138-140]. Abnormal and selective DNA methylation may constitute a potential biomarker and a tool to assess therapeutic treatments at the same time. The data on OS-mediated alterations in DNA methylation, which have been so far obtained, motivate chemoprevention trials, to reduce OS in cancer diseases [141-143]. In human aging, the telomerase reverse transcriptase (hTERT) controls the mitochondrial function and the cellular metabolism, besides the telomeres structure. The enzyme is regulated by DNA methylation. Various observations demonstrate that hTERT may confer major sensitivity towards OS [144] and reduce ROS increase in aging and age-related diseases [145]. Examples of both ROS levels and DNA methylation, which seems to change with age, suggest that they are potentially linked $[146,147]$. ROS-induced methylation at SOD2 gene promoter causes the decreased expression of the gene, which may be associated with the disruption of the cardiorespiratory homeostasis, a typical problem of the old humans. Treatments with DNA methylation inhibitors, in preclinical studies, can prevent the hypoxic sensitivity that leads to the respiratory dysfunction [148]. Also, both ROS-induced 8-OHdG and 5-methyl cytosine generate abnormal GC regions in the DNA, which undergo further methylation and oxidation, thus hampering DNA repair enzymes. These regions have been demonstrated to hit gene expression and DNA susceptibility to damage in Alzheimer's pathology [149].

In complex, ROS are involved in DNA methylation processes in different conditions, occurring in the human aging. The epigenetic machinery operates as OS sensor, which contributes to the OS control and, at the same time, orchestrates the progressive homeostasis impairment, which shapes the cardiovascular, respiratory, and nervous systems of old human beings [146]. The ROS signaling in the DNA methylation during the aging process deserves to be more deeply studied. 


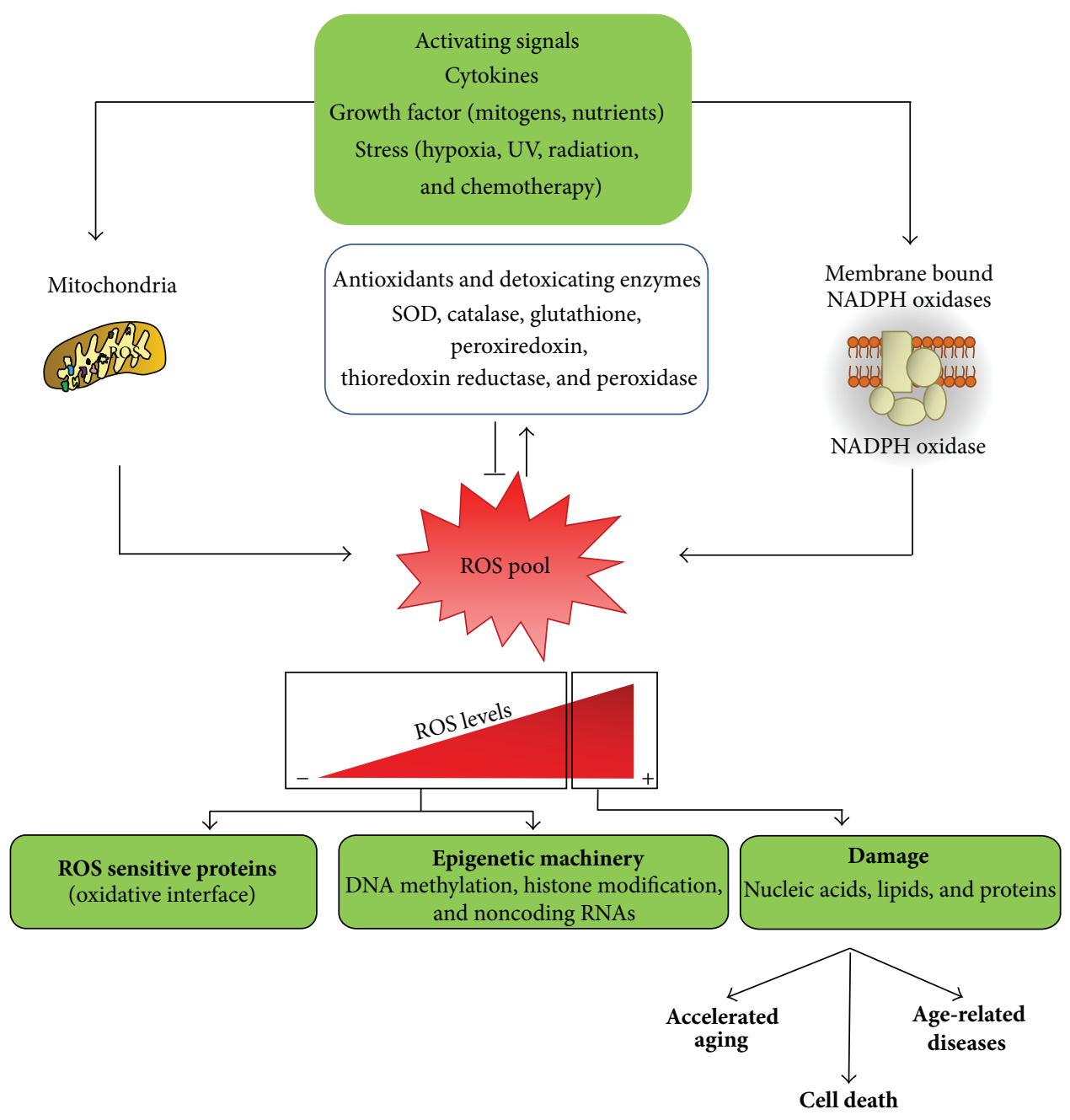

FIGURE 1: Schematic representation of ROS signaling in physiological and pathological conditions. Low and medium ROS levels produced by mitochondria and NADPH oxidase activate cell ROS sensitive proteins and epigenetic machinery. High ROS level causes nucleic acids, lipid, and proteins damage possibly involved in accelerated aging, cell death, and age-related diseases.

\section{ROS in Cell Senescence}

The cell senescence has indicated the irreversible G1 growth arrest of normal primary cells, which occurs after the cells have accumulated time-dependent damage, during extensive culture passages ("replicative senescence"). The cells resist apoptosis and face malignant progression through cytostasis, thus causally contributing to cell senescence induction and maintenance. The senescent cells are able to diversify constantly, like cancer cells, but missing proliferation as a driver [7,9]. Large and flat shape, rich cytoplasmic and vacuolar granularity, high levels of lysosomal $\beta$-galactosidase activity (SA- $\beta$ gal), p16, p21, macroH2A, IL-6, phosphorylated p38MAPK, and "double-strand breaks" are the most common senescent cells features in in situ assays [9]. The exact mechanisms underlying the cell senescence onset and stabilization are still obscure. OS, mitochondrial deterioration, DNA damage, oncogenes expression, and loss of tumor suppressor genes, like PTEN, RB1, NF1, and INPP4, can induce cell senescence [9]. "Replicative senescence," which is provoked by endogenous stimuli, is distinct from "stressinduced premature senescence," which is provoked by exogenous stimuli. The two processes share molecular and functional features, although they are dependent, or not, on telomeres status, respectively. Intrinsic and extrinsic events can induce either the cell senescence or the apoptosis process, depending on the level of the impairment of the cell homeostasis [150] and the p53 activity [47]. The molecules secreted by senescent cells (secretoma) cooperate deeply to maintain the tissues homeostasis, through autocrine and paracrine activities [151], by acting at multiple levels: epigenome [152], gene expression, protein processing, and metabolic control [153]. Moreover, specific mitochondrial pathways contribute to priming the senescence process, through the alteration of the mitochondrial redox state $[6,151]$. The senescence secretoma acts in physiological and pathological events, as tissue remodeling during embryogenesis, tissue repair in wound healing, and induction of aging, as well as age-related diseases of different organisms. The secretoma develops beneficial effects on carcinogenic DNA lesions of precancerous cells, 
by both preventing their uncontrolled cell proliferation and reacting with specific anticancer compounds [154]. However, the secretoma may provide indispensable cytokines for the cancer cells growth, thus promoting tumorigenesis in definite conditions, which are partly related to the cellular metabolic state [155]. Cause-effect relationships between cellular ROS production and cell senescence have been investigated through diverse pathways that comprise the following.

(i) Mitochondrial DNA (mtDNA) Damage. ROS contribute to cellular senescence onset and progression by damaging mtDNA directly or in synergy with modifications of the telomerase reverse transcriptase (TERT) enzyme and the p53 and Ras pathways activity [9]. Also, ROS production by serial signaling through GADD45-MAPK14 (p38MAPK)GRB2-TGFBR2-TGFb is both necessary and sufficient for the stability of growth arrest, during the establishment of the senescent phenotype [156].

(ii) Signaling Pathways via Ras, p53, p21, and p16. The pathways generate ROS, which act as signaling molecules, without causing oxidative DNA damage. ROS result as a tightly regulated signaling process for the induction of the cell senescence [157].

(iii) Autophagy. High ROS levels mediate p53 activation that induces autophagy inhibition. This event generates mitochondrial dysfunction, which in turn generates cell senescence. The autophagy inhibition causes the senescent cells to aggregate oxidized proteins and protein carbonyls with products of lipid peroxidation and protein glycation into the lipofuscin [158].

(iv) $m i R-210$ and $m i R-494$. The induction of these microRNAs by ROS generates mitochondrial dysfunction and autophagy inhibition [159].

The (iii) and (iv) pathways generate vicious loop cycles in ROS production. Autophagy inhibition causes lipofuscin accumulation, which activates further autophagy impairment and ROS production, consequently. All the factors (i), (ii), (iii), and (iv) may add to DNA damage and dysfunctions of both mitochondria and cell metabolism homeostasis [159]. In vitro and preclinical experiments show that ROS decreasing interventions influence cell senescence progression, via the slowdown of telomere shortening and the extension of the cell lifespan. Replicative telomere exhaustion, DNA damage, and OS prime the cell senescence by sharing the activation of the "DNA Damage Response." ATM or ATR kinases of these signaling pathways cause p53 stabilization and transcriptional activation of the p53 target, p21 [9]. p53 triggers cell cycle arrest by upregulating p21, which inhibits the cell cycle regulator cyclin-dependent kinases $\mathrm{Cdk} 4$ and Cdk2 [159]. Whereas high OS levels induce the prosenescence function of p53, the mild OS levels that are induced by the physical exercise in humans have a positive effect on cell and mitochondrial homeostasis. p53 exerts a dual effect on cell senescence because of its ability to both decrease and increase the cellular OS level [160]. In parallel to "DNA Damage
Response," the mitochondrial p38-MAPK replenishes the short-lived DNA damage foci, via a ROS feedback loop, and induces the senescent secretoma [161].

The occurrence of the ROS role in cell senescence onset and maintenance might be relevant for therapeutic interventions, which aim to modulate ROS levels in cancer cells, as well as in aging processes [156]. Human kidney dysfunctions exemplify progressive stages of ROS-induced cell senescence. ROS act like a sensor in regulating the oxygen-dependent gene expression of the kidney and play a leading role in the inflammatory processes, to which the organ is especially sensitive [162]. In conclusion, the ROS signaling has highlighted key factors for the cell senescence induction and maintenance, which are the object of intensive investigations.

5.1. Cell Senescence in Aging and Age-Related Diseases (ROS Effect). The "replicative cell senescence" is considered an aging hallmark on the basis of two motives: (1) the senescent cells accumulate in organismal tissues, by rate and proportion, which parallel the age advancement; (2) the senescent cells accelerate the age-related decrease of tissue regeneration, through the depletion of stem and progenitors cells $[8,97]$. While the sequence of proliferative arrest (senescence), recruitment of immune phagocytic cells (clearance), and promotion of tissue renewal (regeneration) results in being beneficial upon a damaged tissue, for instance, the sequence is inefficiently completed in aging tissues, causing senescent cells to undergo chronic accumulation [163]. Also, a delicate balance exists between cell senescence positive effects on tumor suppression and negative effects on aging related processes [164]. The transcription factor and tumor suppressor p53 are involved in DNA repair and cellular stress response, as well as cellular cycle control. In addition, p53 modulates both the cell senescence and the aging process, through the coordination of specific cellular pathways [165, 166]. It is not clear whether p53 mechanisms in cell senescence and aging are common [160]. An increased senescence secretoma causes detrimental effects over the years and contributes to the typical disruption of aged tissues $[8,167$, 168]. Senescent cells endowed with the semiselective marker of senescence p16 drive age-related pathologies, which are delayed or prevented by the selective elimination of the senescent cells [169]. A partial list of suggested markers of cell senescence in human tissues, both aged and affected by age-related pathologies, is reported in Table 2 [170-197]. Lungs show a typical example of cell senescence associated with the progressive, age-related organ dysfunction. The OS generated by the potent cigarette oxidants is a key element in the pathogenesis of the pulmonary emphysema, induced by the chronic smoking. The fibroblasts that provide essential support and matrix for lung integrity show reduced proliferation rate and increased SA- $\beta$ gal activity in patients affected by pulmonary emphysema. These senescent fibroblasts contribute to the lung disease by affecting the tissue homeostasis. Also, senescent features of the endothelial cells in chronic smokers associate with premature vessels atherosclerosis. In patients with severe coronary artery disease, OS accelerates the senescence of endothelial cells, which is related to risk factors for cardiovascular disease [198]. A further example 
TABLE 2: Clinical examples of senescence-associated biomarkers detected in organs and tissues of patients affected by age-related diseases.

\begin{tabular}{|c|c|c|}
\hline Organ/tissue & Senescence-associated biomarkers & Clinical references \\
\hline \multicolumn{3}{|l|}{ Cardiovascular diseases } \\
\hline Aged vascular tissues & Telomeres length, SA- $\beta$ Gal, p16, and p 21 & {$[170,171]$} \\
\hline \multicolumn{3}{|l|}{ Atherosclerosis } \\
\hline \multicolumn{3}{|l|}{ Systolic heart failure } \\
\hline \multicolumn{3}{|l|}{ Malignant tumors } \\
\hline Lung cancer & Telomeres length, SA- $\beta$ gal & {$[172,173]$} \\
\hline Breast cancer & $\begin{array}{l}\text { SA- } \beta \text { gal, p21, p16, DEP1, NTAL, EBP50, STX4, VAMP3, } \\
\text { ARMX3, B2MG, LANCL1, VPS26A, and PLD3 }\end{array}$ & {$[174,175]$} \\
\hline Neuroblastoma & SA- $\beta$ gal & [176] \\
\hline Astrocytoma & SA- $\beta$ gal & {$[177]$} \\
\hline Mesothelioma & SA- $\beta$ gal, p21 & {$[178]$} \\
\hline Melanoma & SA- $\beta$ gal, p16, and p 21 & {$[179]$} \\
\hline Prostate cancer & SA- $\beta$ gal, Glbl, and HPlg & {$[154,180]$} \\
\hline Liver cancer & Telomeres length, SA- $\beta$ gal & {$[181]$} \\
\hline Colorectal cancer & Short telomeres & {$[182]$} \\
\hline \multicolumn{3}{|l|}{ Fibrosis } \\
\hline Idiopathic pulmonary fibrosis & Telomeres length, IGFBP5, and SA- $\beta$ gal & {$[183,184]$} \\
\hline Cystic fibrosis & Telomere length, p16 & {$[185]$} \\
\hline Liver fibrosis & Telomere length, IGFBP-5, SA- $\beta$-gal, and p 21 & {$[183,186]$} \\
\hline Renal fibrosis & p16 & {$[187,188]$} \\
\hline \multicolumn{3}{|l|}{ Neurological disorders } \\
\hline Alzheimer's disease & SA- $\beta$-gal & {$[189,190]$} \\
\hline \multicolumn{3}{|l|}{ Other diseases } \\
\hline Chronic obstructive pulmonary disease & Telomere length, p16, p21, and SA- $\beta$ gal & {$[191,192]$} \\
\hline Pulmonary hypertension & p16, p21 & {$[192,193]$} \\
\hline Emphysema & Telomere length, IGFBP-3, IGFBP-rP1, p16INK4a, and p21 & {$[194,195]$} \\
\hline Benign prostatic hyperplasia & SA- $\beta$ gal & {$[196,197]$} \\
\hline
\end{tabular}

of aging dysfunction related to cell senescence is shown by the scaffolding protein Caveolin 1 (Cav1), which controls molecular signaling in caveolar membranes. Cavl promotes cellular senescence in age-related pathologies, by mediating p53 activation with EGF modulation, focal adhesion, and small Rho GTPase-dependent signaling. The upregulation of the Cavl promoter by high ROS levels contributes to explaining how OS promotes cell senescence effects in aging and age-related diseases [198]. In addition, the interplay between different conditions of mitochondrial homeostasis and ROS-dependent signaling pathways contributes to aging process, through the cell senescence induction and stabilization [199]. Yet ROS-independent signaling pathways link dysfunctions in mitochondria and aging, through the cell senescence process $[6,151]$. As a new approach, preclinical and clinical studies demonstrate the therapeutic effects of the aging inhibitor rapamycin, whose signaling pathway is involved in cellular senescence $[160,200]$.

In conclusion, cell senescence reduces the age-related tumor development and contributes to human aging, suggesting that aging might be switched for tumorigenesis [201, 202]. ROS may modulate tumor suppression process, which is induced by the senescence, thus participating in anticancer mechanisms, although ROS may act as tumor promoters in definite conditions [48]. With the cell senescence and aging controlled by cells and cellular environment, the possibility is suggested that the two processes may be subjected to interventional therapies $[203,204]$.

5.2. Epigenetic Mechanism in Cell Senescence (ROS Involvement). The epigenetic control of acute and chronic cellular senescence allows for the two processes that are involved in various conditions that lead to the cells longevity preventing cell death and tumorigenesis [205]. The abrogation of tumor suppressor pathways, as p53 and p16/Rb, bypasses the cell senescence, thus leading to the tumorigenic phenotypes acquiring [206]. The mechanisms that balance the transcriptional state of the chromatin are not fully understood. Some regulative changes involve the histone proteins that coordinate the DNA accessibility, through transcription factors, besides the DNA replication and repair. The Polycomb Repressor Complex 2 (PRC2) initiates and preserves specific histone methylations, thus acting as an epigenetic mark that mediates targeted genes [207]. The repression of the histone activity by the Polycomb Group (PcG) proteins causes gene silencing, but it can be countered by specific demethylases, 
which erases the methyl mark [208]. The upregulation of many PRC target genes leads to global epigenetic changes [209-211]. Specific transcription factors [212], as well as long noncoding RNAs [213], are involved in the recruitment performed by PRC. PRC2 takes a crucial part in silencing the locus of p16, the marker that is upregulated during cell senescence [212]. The reversal of chromatin epigenetic pattern via deacetylation, demethylation, and dephosphorylation is significantly involved in underscoring both flexible and dynamic nature of histone modifications [214]. The histone demethylases JMJD3 produce diverse outputs of biological function, depending on the action of their transcriptional complexes. Different expression of these demethylases, which have tumor suppressor activities during the "stress-induced senescence" $[215,216]$, is reflected into cellular phenotype changes and variations associated with cellular senescence [217]. The JMJD3 gene is located near the p53 tumor suppressor gene, that is, a genomic area that is frequently lost in various malignancies. The SIRT1 histone deacetylase (SIRT1) is a known regulator of age-related diseases that regulates the senescence secretoma components, by silencing their promoter regions epigenetically. SIRT1 plays a pivotal role in stress modulation also through p53 deacetylation, acting against aging and agerelated diseases. As indicated above, the high ROS levels activate $\mathrm{p} 53$, which, in turn, activates $\mathrm{p} 53$-mediated apoptosis and cell senescence. Moreover, SIRT1 regulates the ROSdependent FOXO factors, which are responsible for cell growth, proliferation, and longevity. The characteristic ROS increase during aging may be responsible for the decreased SIRT1 activity, which facilitates the senescent-like phenotype. SIRT1 causes oxidant effects, as well as antioxidant effects, by acting on epigenetic modifications, which include acetylation and deacetylation (see references in $[128,146])$. Experiments on cell senescence induction show different molecular mechanisms in acute versus chronic senescent cells. A better knowledge of the order in which epigenetics mechanisms change during the cell senescence progression, from initial towards full senescence, is believed to be vital for finding therapies against age-related disorders [9].

5.2.1. Noncoding RNA. Latest genomics tools and sequencing approaches have helped unravel large chromosomes stretches, which were previously deemed not transcribed $[218,219]$. These sequence regions contain noncoding RNA (ncRNA), which is known as long lncRNAs, and short ncRNAs. Among short ncRNAs, the microRNAs (miRNAs) have emerged as being able to control the gene expression, either by blocking targeted mRNA translation or by mRNA degrading $[220,221]$. Recently, ncRNA role is gaining more importance in age-associated dysfunctions as cardiovascular diseases [222, 223]. The senescence-associated lncRNAs are differentially expressed in proliferating and senescent fibroblasts, as assessed by RNA sequencing [224-226]. Toxicological studies associate increased ROS production with increased expression of a set of 115 lncRNAs, which significantly affect p53 signaling pathway [227]. A mitochondrialtranscribed lncRNA is induced in aorta and endothelial cells aging, during the "replicative vascular senescence," which is partly responsible for age-associated cardiovascular diseases, but not in the "stress-induced premature senescence" by ROS [228].

5.2.2. microRNA ( $m i R N A, m i R$ ). Normal cellular development and homeostasis are under the control of miRNAs, throughout the entire life [229], since miRNAs regulate the gene expression in biological processes as proliferation, development, differentiation, and apoptosis. Yet several miRNAs families control cell senescence at multiple levels, by regulating the autophagy process and the gene expression involved in ATP and ROS production. Some miRNAs may induce ROS production that generates a self-sustaining ROS vicious cycle [159]. miRNAs constitute a connection between aging, cell senescence, and cancer. The miRNAs dysregulation causes the activation of pathways they normally repress. The event may activate aberrant pathways and also aging mechanism in young individuals [222]. Although current studies are monitoring miRNA tissues and systemic alterations, instead of miRNA changes through lifespan and metabolic modifications, several profiles of miRNA expression demonstrate changes during the aging. As an example, miR-29, which targets the genes of type IV collagen and maintains the structure of the extracellular matrix, increases in elderly mice, thus causing collagen decreasing, a tissues basement membranes weakening [230]. Only few miRNAs have been directly linked to age-related changes in cellular and organ functions, whereas many miRNAs have been directly connected with disease states. It is unclear if the modifications of miRNA profiles are mostly involved in pathological changes onset or if they mark the senescence end, which leads to the organ aging and dysfunction. Altered expression in miRNA activity has been observed in elderly people, as in the case of miR-34a, which belongs to a family with conserved functions in controlling aging and age-related diseases [203, 231, 232]. miR-34a targets ROS scavenger enzymes inducing OS [159]. The miR-34a upregulation or overexpression has been associated with cell proliferation inhibition, subsequent cell senescence induction, and premature death, in both endothelial progenitor and mature cells. miR-34a causes memory function impairment when it is upregulated in aged mice and in models for Alzheimer's disease (AD), while miR-34a targeting restores the memory function [233]. Also, the miR-34 mutation of the lossof-function delays the age-related decline markedly, thus resulting in extended lifespan and increased resistance to the heat and the OS. The human miR-34a is downregulated in Parkinson's disease brain, while it is upregulated in AD brains [234] and in plasma of Huntington's disease patients [235].

Several miRNA families are modulated by ROS in the development of mitochondria-mediated cell senescence, which are, indirectly or directly, implicated in human pathologies. Little is known about the roles of ROSmodulated miRNAs in cell function. The molecular mechanisms that control neuronal response to OS have been deeply studied in different strains of senescence accelerated mice, based on the consideration that OS plays a critical role in $\mathrm{AD}$ etiology and pathogenesis. OS upregulates a group of miRNAs (miR-329, miR-193b, miR-20a, miR-296, and miR-130b), which is associated with affecting 83 target genes. Among the 
genes, mitogen-activated protein kinase signaling pathway has been suggested to play a role in pathogenesis of neurodegenerative diseases [233]. OS effects on vascular homeostasis, including angiogenesis in physiological processes and agerelated diseases, are largely studied in human umbilical vein endothelial cells (HUVECs), considering that miRNAs modulate endothelial cells response to OS. ROS induce the expression of miR-200 family members (miR-200c, miR141, miR-200a, miR-200b, and miR-429), which determines apoptosis and cell senescence both in HUVEC cells and in a model of hind limb ischemia, which shows OS-mediated mechanism [236]. The miR-200 family plays a causative role in the vascular diabetic inflammatory phenotype in a diabetic model and in the human vasculopathy disease, suggesting that miR-200 inhibition might represent a therapeutic target to prevent OS negative effects on cell function and survival [146]. Also, miR-200 family has been extensively studied in epithelial-to-mesenchymal transition of cancer cells [236]. Lately, miR-760 and miR-186 upregulation has been associated with replicative senescence in human lung fibroblast cells. These miRNAs cooperate to induce senescence through the ROS-p53-p21Cip1/WAF1 pathway, which depends on the ROS generated by the downregulation of the protein kinase 2 (CK2 $\alpha$ ). A better understanding of the mechanisms of CK2 regulation might provide new therapeutic options to restore the function of lungs in aged people. An example of the increasing evidence that miRNAs are critically involved in the posttranscriptional regulation of cell functions, including the ROS signaling modulation, is underlined in Figure 2.

\section{Conclusion and Future Perspectives}

The multifactorial and inexorable phenomenon of aging worsens the human functions at multiple levels, causing a gradual reduced ability to resist stress, damage, and illness. Healthy aging appears to be an ideal healthcare priority that entails a better understanding of aging, with the aim of slowing down the process and preventing or even treating its related pathologies [200]. Indeed, genetic insights combined with findings from animal and cellular models have advanced our understanding of pathways that lead to agerelated features, highlighting possible interventional targets [2-5]. The cellular senescence process is considered an aging hallmark, because it drives the cells through longevity, by hampering tumorigenesis and cell death, and is involved in many age-related diseases $[97,205,206]$. The cell senescence is a feature that characterizes somatic cells, except for most tumor cells and certain stem cells [6-10]. The senescent cells produce a specific secretoma that cause beneficial effects, through its autocrine and paracrine mechanisms. When the senescent cell program is inefficiently developed, as it occurs during the aging, the secretoma causes detrimental effects [151-153, 167, 168, 199]. In the recent years, evidence has been accumulating that ROS, which include $\mathrm{H}_{2} \mathrm{O}_{2}$, superoxide, anion, and hydroxyl radicals, generated from both intrinsic and extrinsic events, inhibit cell growth and induce cell death and senescence in a context-dependent manner [157, 236]. Through the understanding of the ROS role as signaling molecules in a myriad of signaling pathways, ROS levels are no longer considered as mere metabolic byproducts but are believed to be a "redox biology" that regulates physiological functions, including signal transduction, gene expression, and proliferation [37]. Firstly, it has been evidenced that the DNA damage caused by ROS acting as mutating agents contributes to the induction and maintenance of the cell senescence process $[9,156]$. More recently, particular attention has been focused on the ROS involvement as signaling molecules in cell senescence induction, without causing DNA damage. Signaling pathways via Ras, p53, p21, and p16 have been defined to generate ROS, which may act as tightly regulated process contributing to the cell senescence induction $[20,157$, 158]. Cause-effect relationships between cell ROS production and cell senescence have been investigated through diverse pathways that include the field of mitochondrial DNA and autophagy inhibition and the effects of the microRNAs miR210 and miR-494 in various mitochondrial processes [159]. These pathways highlight ROS contribution to prime cell senescence at diverse levels, among which epigenetic level is attracting more and more attention in studies aimed at the senescence control $[227,233,236]$. Indeed, the epigenetic modulation provides the essential and flexible interface between the organisms and the environment, which results in being essential for all the cell functions [122, 123, 129], throughout the lifespan [135-137]. A major breakthrough in the last decades has been the understanding that epigenetics contribute to human diseases development.

In parallel, the "OS theory of aging" remains the most documented mechanistic hypothesis of aging, although it does not necessarily imply ROS imbalance as the earliest trigger or the main cause of aging [98-103]. Therapeutic ROS modulation is suggested as relevant in aging and related events [95, 96, 114]. Also, the senescent cells have been identified as a novel potential therapeutic target in the aging and age-related diseases $[169,171]$. Further research is needed to define when and where cell senescence results in being favorable or unfavorable to organismal health. Both proand antisenescent therapies can be equally helpful, when they are opportunely modulated and balanced. Prosenescent therapies contribute to minimize damage in the cancer disease and in the active tissue repair by limiting proliferation and fibrosis, respectively, while antisenescent therapies may help to eliminate accumulated senescent cells and to recover tissue function. The current research points to a double objective: to define the changes about the redox-sensitive cell pathways and to define the OS role in linking environmental factors with epigenetic modifications.

Particular emphasis is addressed to novel mechanism of ROS and epigenetics in cell senescence and aging [160, 165, 166]. The histone demethylases network is often synergizing with the action of histone deacetylases, histone methyl transferases, and various nuclear transcriptional complexes, thus ensuring that the chromatinic environment is correct for the cell $[128,146]$. Preclinical and clinical examples of ROS-dependent epigenetic modifications [125-127, 130$134,138]$ extend their effects to aging $[135,136]$ and agerelated diseases [137, 142-144, 146-149], particularly towards cancer disease [139-141, 145]. Among the noncoding RNAs, miRNAs families provide a broad silencing activity of mRNA 


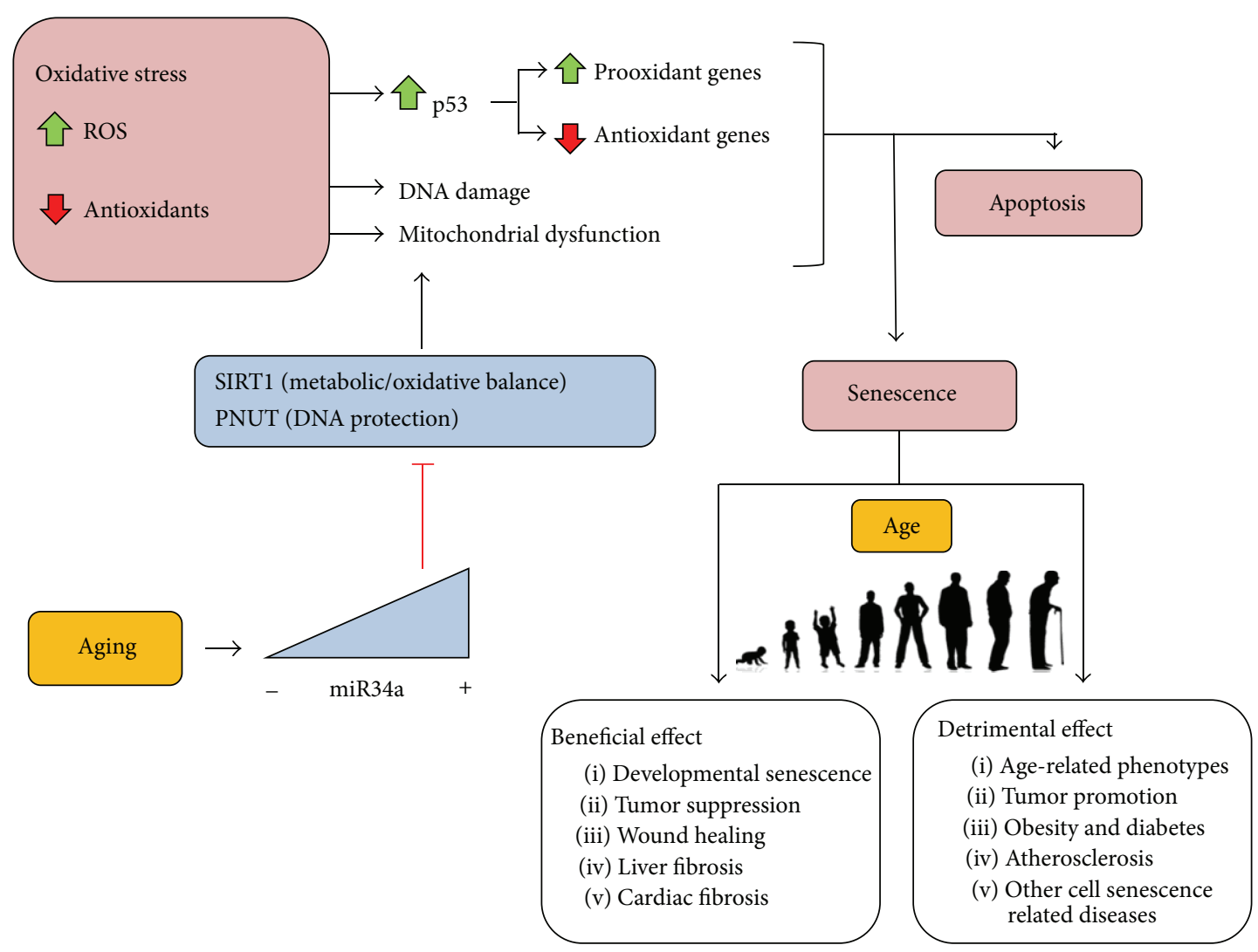

FIgURE 2: ROS-mediated senescence. Besides causing DNA damage and mitochondria dysfunction, OS activates p53 that, in turn, induces prooxidant genes and imbalances antioxidant genes induction. The set of alterations caused by ROS lead to induction of cell senescence, which, in turn, can develop both positive and negative effects; miR34a expression increases with aging in many tissues downregulating SIRT1 protein activity (a longevity promoting factor) and PNUT protein (a DNA protecting factor which prevents telomere attrition and is involved in tissues repairs).

targets, in a sequence dependent fashion that modulates the stress response [159]. Accumulating evidences show that stressors, including ROS, potentially alter the function of miRNA-processing in aging organisms, which renders the cells even more prone to stress, linking aging and cancer. Several miRNAs families induce ROS level increase in aging or target factors involved in the ROS signaling. In addition, ROS increase highly correlates with a specific miRNA dysregulation, which mediates the cross talk between p53, NF$\kappa \mathrm{B}$ p65, and ROS. All these events have been associated with cell senescence $[203,231,232]$. At the same time, certainly several miRNAs families are modulated by ROS in the development of mitochondria-mediated cell senescence, which are, indirectly or directly, implicated in human pathologies $[159,233,236]$. Because epigenome is so tightly regulated and complex, understanding individual modifications and their network of interaction offers the potential to design drugs that are very effective therapies against a number of diseases [124, 203-205, 219-222]. More reliable OS biomarkers, as well as OS related epigenetic mechanisms, have emerged over the last years as potentially useful tools to design therapeutic approaches aimed at modulating in vivo enhanced OS.

\section{Abbreviations}

$\begin{array}{ll}\text { AP-1: } & \text { Activator protein-1 } \\ \text { DDR: } & \text { DNA Damage Response } \\ \text { FOXO3a: } & \text { Forkead homeobox type O } \\ \text { HIF-1a: } & \text { Hypoxia inducible factor-la } \\ \text { hTERT: } & \text { Human telomerase reverse transcriptase } \\ \text { miRNA, miR: } & \text { MicroRNA } \\ \text { JAK/STAT: } & \text { Janus kinase/signal transducers and } \\ & \text { activators of transcription } \\ \text { Nox: } & \text { NADPH oxidases } \\ \text { NF- } \kappa \text { B: } & \text { Nuclear factor kappa B } \\ \text { NS: } & \text { Nitrosative stress } \\ \text { Nrf2-ARE: } & \text { NF-E2-related factor 2 binding to the } \\ & \text { antioxidant responsive elements } \\ \text { p53: } & \text { Tumor suppressor p53 } \\ \text { OS: } & \text { Oxidative stress } \\ \text { PPAR } \gamma: & \text { Peroxisome proliferator-activated receptor } \\ & \text { gamma } \\ \text { RNS: } & \text { Reactive Nitrosative Species } \\ \text { ROS: } & \text { Reactive Oxygen Species } \\ \text { SA- } \beta \text { gal: } & \text { Senescence-associated } \beta \text {-galactosidase } \\ \text { SOD: } & \text { Superoxide dismutase. }\end{array}$




\section{Competing Interests}

The authors declare that they have no competing interests.

\section{Acknowledgments}

The authors sincerely apologize to colleagues whose work they could not include due to space limitations.

\section{References}

[1] C. A. Werner, “The older population: 2010," https://www.census .gov/prod/cen2010/briefs/c2010br-09.pdf.

[2] D. B. Lynch, "The role of the microbiota in ageing: current state and perspectives," WIREs Systems Biology and Medicine, vol. 7, pp. 131-138, 2015.

[3] A. H. Shadyab and A. Z. LaCroix, "Genetic factors associated with longevity: a review of recent findings," Ageing Research Reviews, vol. 19, pp. 1-7, 2015.

[4] P. V. Sergiev, O. A. Dontsova, and G. V. Berezkin, "Theories of aging: an ever-evolving field," Acta Naturae, vol. 7, no. 1, pp. 918, 2015.

[5] M. Ristow and S. Schmeisser, "Extending life span by increasing oxidative stress," Free Radical Biology and Medicine, vol. 51, no. 2, pp. 327-336, 2011.

[6] C. Correia-Melo and J. F. Passos, "Mitochondria: are they causal players in cellular senescence?" Biochimica et Biophysica ActaBioenergetics, vol. 1847, no. 11, pp. 1373-1379, 2015.

[7] T. Kuilman, C. Michaloglou, W. J. Mooi, and D. S. Peeper, "The essence of senescence," Genes \& Development, vol. 24, no. 22, pp. 2463-2479, 2010.

[8] J. Campisi and L. Robert, "Cell senescence: role in aging and age-related diseases," Interdisciplinary Topics in Gerontology, vol. 39, pp. 45-61, 2014.

[9] J. M. Van Deursen, "The role of senescent cells in ageing," Nature, vol. 509, no. 7501, pp. 439-446, 2014.

[10] C. B. Newgard and N. E. Sharpless, "Coming of age: molecular drivers of aging and therapeutic opportunities," The Journal of Clinical Investigation, vol. 123, no. 3, pp. 946-950, 2013.

[11] D. G. Hirst and T. Robson, "Nitric oxide physiology and pathology," Methods in Molecular Biology, vol. 704, pp. 1-13, 2011.

[12] C. L. Quinlan, I. V. Perevoshchikova, M. Hey-Mogensen, A. L. Orr, and M. D. Brand, "Sites of reactive oxygen species generation by mitochondria oxidizing different substrates," Redox Biology, vol. 1, no. 1, pp. 304-312, 2013.

[13] M. Fransen, M. Nordgren, B. Wang, and O. Apanasets, "Role of peroxisomes in ROS/RNS-metabolism: implications for human disease," Biochimica et Biophysica Acta-Molecular Basis of Disease, vol. 1822, no. 9, pp. 1363-1373, 2012.

[14] J. D. Lambeth and A. S. Neish, "Nox enzymes and new thinking on reactive oxygen: a double-edged sword revisited," Annual Review of Pathology: Mechanisms of Disease, vol. 9, pp. 119-145, 2014.

[15] M. V. Chuong Nguyen, B. Lardy, M.-H. Paclet et al., "NADPH oxidases, Nox: new isoenzymes family," Medecine/Sciences, vol. 31, no. 1, pp. 43-52, 2015.

[16] X. De Deken, B. Corvilain, J. E. Dumont, and F. Miot, "Roles of DUOX-mediated hydrogen peroxide in metabolism, host defense, and signaling," Antioxidants and Redox Signaling, vol. 20, no. 17, pp. 2776-2793, 2014.
[17] A. Phaniendra, D. B. Jestadi, and L. Periyasamy, "Free radicals: properties, sources, targets, and their implication in various diseases," Indian Journal of Clinical Biochemistry, vol. 30, no. 1, pp. 11-26, 2015.

[18] G. Bresciani, I. B. da Cruz, and X. González-Gallego, "Manganese superoxide dismutase and oxidative stress modulation," Journal of Advanced Clinical Chemistry, vol. 68, pp. 87-130, 2015.

[19] A. Pompella and A. Corti, "Editorial: the changing faces of glutathione, a cellular protagonist," Frontiers in Pharmacology, vol. 6, article 98, 2015.

[20] B. Halliwell, "Free radicals and antioxidants: updating a personal view," Nutrition Reviews, vol. 70, no. 5, pp. 257-265, 2012.

[21] A. Rahal, A. Kumar, V. Singh et al., "Oxidative stress, prooxidants, and antioxidants: the interplay," BioMed Research International, vol. 2014, Article ID 761264, 19 pages, 2014.

[22] E. Ginter, V. Simko, and V. Panakova, "Antioxidants in health and disease," Bratislava Medical Journal, vol. 115, no. 10, pp. 603606, 2014.

[23] M. Abo, R. Minakami, K. Miyano et al., "Visualization of phagosomal hydrogen peroxide production by a novel fluorescent probe that is localized via SNAP-tag labeling," Analytical Chemistry, vol. 86, no. 12, pp. 5983-5990, 2014.

[24] D. Kim, G. Kim, S.-J. Nam, J. Yin, and J. Yoon, "Visualization of endogenous and exogenous hydrogen peroxide using a lysosome-targetable fluorescent probe," Scientific Reports, vol. 5, article 8488, 2015.

[25] X. Zhou, Y. Kwon, G. Kim, J.-H. Ryu, and J. Yoon, "A ratiometric fluorescent probe based on a coumarin-hemicyanine scaffold for sensitive and selective detection of endogenous peroxynitrite," Biosensors and Bioelectronics, vol. 64, pp. 285-291, 2015.

[26] G. Y. Liou and P. Storz, "Detecting reactive oxygen species by immunohistochemistry," in Stress Responses, vol. 1292 of Methods in Molecular Biology, pp. 97-104, Springer, 2015.

[27] E. Cabiscol, J. Tamarit, and J. Ros, "Protein carbonylation: proteomics, specificity and relevance to aging," Mass Spectrometry Reviews, vol. 33, no. 1, pp. 21-48, 2014.

[28] H. E. Poulsen, L. L. Nadal, K. Broedbaek, P. E. Nielsen, and A. Weimann, "Detection and interpretation of 8-oxodG and 8oxoGua in urine, plasma and cerebrospinal fluid," Biochimica et Biophysica Acta (BBA)_General Subjects, vol. 1840, no. 2, pp. 801-808, 2014.

[29] D. A. Butterfield, L. Gu, F. Di Domenico, and R. A. S. Robinson, "Mass spectrometry and redox proteomics: applications in disease," Mass Spectrometry Reviews, vol. 33, no. 4, pp. 277-301, 2014.

[30] L. M. Fan and J.-M. Li, "Evaluation of methods of detecting cell reactive oxygen species production for drug screening and cell cycle studies," Journal of Pharmacological and Toxicological Methods, vol. 70, no. 1, pp. 40-47, 2014.

[31] A. Cossarizza, R. Ferraresi, L. Troiano et al., "Simultaneous analysis of reactive oxygen species and reduced glutathione content in living cells by polychromatic flow cytometry," Nature Protocols, vol. 4, no. 12, pp. 1790-1797, 2009.

[32] H. Miki and Y. Funato, "Regulation of intracellular signalling through cysteine oxidation by reactive oxygen species," Journal of Biochemistry, vol. 151, no. 3, pp. 255-261, 2012.

[33] D. W. Bak and E. Weerapana, "Cysteine-mediated redox signalling in the mitochondria," Molecular BioSystems, vol. 11, no. 3, pp. 678-697, 2015.

[34] C. C. Winterbourn and M. B. Hampton, "Thiol chemistry and specificity in redox signaling," Free Radical Biology and Medicine, vol. 45, no. 5, pp. 549-561, 2008. 
[35] T. Finkel, "From sulfenylation to sulfhydration: what a thiolate needs to tolerate," Science Signaling, vol. 5, no. 215, article pe10, 2012.

[36] T. H. Truong and K. S. Carroll, "Redox regulation of protein kinases," Critical Reviews in Biochemistry and Molecular Biology, vol. 48, no. 4, pp. 332-356, 2013.

[37] M. Schieber and N. S. Chandel, "ROS function in redox signaling and oxidative stress," Current Biology, vol. 24, no. 10, pp. R453-R462, 2014.

[38] J. Korbecki, I. Baranowska-Bosiacka, I. Gutowska, and D. Chlubek, "The effect of reactive oxygen species on the synthesis of prostanoids from arachidonic acid," Journal of Physiology and Pharmacology, vol. 64, no. 4, pp. 409-421, 2013.

[39] A. Corcoran and T. G. Cotter, "Redox regulation of protein kinases," FEBS Journal, vol. 280, no. 9, pp. 1944-1965, 2013.

[40] G. A. Knock and J. P. T. Ward, "Redox regulation of protein kinases as a modulator of vascular function," Antioxidants \& Redox Signaling, vol. 15, no. 6, pp. 1531-1547, 2011.

[41] J. W. Zmijewski, S. Banerjee, H. Bae, A. Friggeri, E. R. Lazarowski, and E. Abraham, "Exposure to hydrogen peroxide induces oxidation and activation of AMP-activated protein kinase," The Journal of Biological Chemistry, vol. 285, no. 43, pp. 33154-33164, 2010.

[42] S. Wang, P. Song, and M.-H. Zou, "AMP-activated protein kinase, stress responses and cardiovascular diseases," Clinical Science, vol. 122, no. 12, pp. 555-573, 2012.

[43] P. D. Ray, B.-W. Huang, and Y. Tsuji, "Reactive oxygen species (ROS) homeostasis and redox regulation in cellular signaling," Cellular Signalling, vol. 24, no. 5, pp. 981-990, 2012.

[44] A. F. Chen, D.-D. Chen, A. Daiber et al., "Free radical biology of the cardiovascular system," Clinical Science, vol. 123, no. 2, pp. 73-91, 2012.

[45] C. Caliceti, P. Nigro, P. Rizzo, and R. Ferrari, "ROS, Notch, and Wnt signaling pathways: crosstalk between three major regulators of cardiovascular biology," BioMed Research International, vol. 2014, Article ID 318714, 8 pages, 2014.

[46] B. Liu, Y. Chen, and D. K. St Clair, "ROS and p53: a versatile partnership," Free Radical Biology \& Medicine, vol. 44, no. 8, pp. 1529-1535, 2008.

[47] A. V. Budanov, "The role of tumor suppressor p53 in the antioxidant defense and metabolism," in Mutant p53 and MDM2 in Cancer, vol. 85 of Subcellular Biochemistry, pp. 337-358, Springer, Berlin, Germany, 2014.

[48] B. Vurusaner, G. Poli, and H. Basaga, "Tumor suppressor genes and ROS: complex networks of interactions," Free Radical Biology and Medicine, vol. 52, no. 1, pp. 7-18, 2012.

[49] L. E. Tebay, H. Robertson, S. T. Durant et al., "Mechanisms of activatio nof the transcription factor Nrf2 by redox stressors, nutrient cues, and energy status and the pathways through which it attenuates degenerative disease," Free Radical Biology \& Medicine B, vol. 88, pp. 108-146, 2015.

[50] P. Storz, "Forkhead homeobox type O transcription factors in the responses to oxidative stress," Antioxidants and Redox Signaling, vol. 14, no. 4, pp. 593-605, 2011.

[51] T. Kietzmann and A. Görlach, "Reactive oxygen species in the control of hypoxia-inducible factor-mediated gene expression," Seminars in Cell \& Developmental Biology, vol. 16, no. 4-5, pp. 474-478, 2005.

[52] N. R. Madamanchi and M. S. Runge, "Redox signaling in cardiovascular health and disease," Free Radical Biology and Medicine, vol. 61, pp. 473-501, 2013.
[53] M. J. Morgan and Z.-G. Liu, "Crosstalk of reactive oxygen species and NF- $\kappa$ B signaling," Cell Research, vol. 21, no. 1, pp. 103-115, 2011.

[54] H.-J. K. Hawkes, T. C. Karlenius, and K. F. Tonissen, "Regulation of the human thioredoxin gene promoter and its key substrates: a study of functional and putative regulatory elements," Biochimica et Biophysica Acta (BBA)-General Subjects, vol. 1840, no. 1, pp. 303-314, 2014.

[55] N. Bakunina, C. M. Pariante, and P. A. Zunszain, "Immune mechanisms linked to depression via oxidative stress and neuroprogression," Immunology, vol. 144, no. 3, pp. 365-373, 2015.

[56] E. H. Verbon, J. A. Post, and J. Boonstra, "The influence of reactive oxygen species on cell cycle progression in mammalian cells," Gene, vol. 511, no. 1, pp. 1-6, 2012.

[57] P. Chiarugi, "From anchorage dependent proliferation to survival: lessons from redox signalling," IUBMB Life, vol. 60, no. 5, pp. 301-307, 2008.

[58] G. Liu, E. Chan, M. Higuchi, G. Dusting, and F. Jiang, "Redox mechanisms in regulation of adipocyte differentiation: beyond a general stress response," Cells, vol. 1, no. 4, pp. 976-993, 2012.

[59] G. Serviddio, F. Bellanti, and G. Vendemiale, "Free radical biology for medicine: learning from nonalcoholic fatty liver disease," Free Radical Biology and Medicine, vol. 65, pp. 952-968, 2013.

[60] E. Araki and T. Nishikawa, "Oxidative stress: a cause and therapeutic target of diabetic complications," Journal of Diabetes Investigation, vol. 1, no. 3, pp. 90-96, 2010.

[61] V. O. Kaminskyy and B. Zhivotovsky, "Free radicals in cross talk between autophagy and apoptosis," Antioxidants \& Redox Signaling, vol. 21, no. 1, pp. 86-102, 2014.

[62] E. Migliaccio, M. Giorgio, and P. G. Pelicci, "Apoptosis and aging: role of p66Shc redox protein," Antioxidants \& Redox Signaling, vol. 8, no. 3-4, pp. 600-608, 2006.

[63] E. De Marchi, F. Baldassari, A. Bononi, M. R. Wieckowski, and P. Pinton, "Oxidative stress in cardiovascular diseases and obesity: role of p66Shc and protein kinase C," Oxidative Medicine and Cellular Longevity, vol. 2013, Article ID 564961, 11 pages, 2013.

[64] A. Magenta, S. Greco, M. C. Capogrossi, C. Gaetano, and F. Martelli, "Nitric oxide, oxidative stress, and $\mathrm{p} 66^{\text {Shc }}$ interplay in diabetic endothelial dysfunction," BioMed Research International, vol. 2014, Article ID 193095, 16 pages, 2014.

[65] S. Aleshin, M. Strokin, M. Sergeeva, and G. Reiser, "Peroxisome proliferator-activated receptor $(\mathrm{PPAR}) \beta / \delta$, a possible nexus of PPAR $\alpha$ - and PPAR $\gamma$-dependent molecular pathways in neurodegenerative diseases: review and novel hypotheses," Neurochemistry International, vol. 63, no. 4, pp. 322-330, 2013.

[66] A. Popa-Wagner, S. Mitran, S. Sivanesan, E. Chang, and A.-M. Buga, "ROS and brain diseases: the good, the bad, and the ugly," Oxidative Medicine and Cellular Longevity, vol. 2013, Article ID 963520, 14 pages, 2013.

[67] S. Ventre, A. Indrieri, C. Fracassi et al., "Metabolic regulation of the ultradian oscillator Hes1 by reactive oxygen species," Journal of Molecular Biology, vol. 427, no. 10, pp. 1887-1902, 2015.

[68] A. Maillet and S. Pervaiz, "Redox regulation of p53, redox effectors regulated by p53: a subtle balance," Antioxidants \& Redox Signaling, vol. 16, no. 11, pp. 1285-1294, 2012.

[69] R. Elkholi and J. E. Chipuk, "How do I kill thee? Let me count the ways: P53 regulates PARP-1 dependent necrosis," BioEssays, vol. 36, no. 1, pp. 46-51, 2014. 
[70] J. Trujillo, L. F. Granados-Castro, C. Zazueta, A. C. AndéricaRomero, Y. I. Chirino, and J. Pedraza-Chaverrí, "Mitochondria as a target in the therapeutic properties of curcumin," Archiv der Pharmazie, vol. 347, no. 12, pp. 873-884, 2014.

[71] S. Kovac, P. R. Angelova, K. M. Holmström, Y. Zhang, A. T. Dinkova-Kostova, and A. Y. Abramov, "Nrf2 regulates ROS production by mitochondria and NADPH oxidase," Biochimica et Biophysica Acta (BBA)-General Subjects, vol. 1850, no. 4, pp. 794-801, 2015.

[72] S. Ichihara, "The pathological roles of environmental and redox stresses in cardiovascular diseases," Environmental Health and Preventive Medicine, vol. 18, no. 3, pp. 177-184, 2013.

[73] L.-O. Klotz, C. Sánchez-Ramos, I. Prieto-Arroyo, P. Urbánek, H. Steinbrenner, and M. Monsalve, "Redox regulation of FoxO transcription factors," Redox Biology, vol. 6, pp. 51-72, 2015.

[74] B. Ponugoti, G. Dong, and D. T. Graves, "Role of forkhead transcription factors in diabetes-induced oxidative stress," Experimental Diabetes Research, vol. 2012, Article ID 939751, 7 pages, 2012.

[75] J. Tanaka, L. Qiang, A. S. Banks et al., "Foxol links hyperglycemia to LDL oxidation and endothelial nitric oxide synthase dysfunction in vascular endothelial cells," Diabetes, vol. 58, no. 10, pp. 2344-2354, 2009.

[76] Y. Funato and H. Miki, "Redox regulation of Wnt signalling via nucleoredoxin," Free Radical Research, vol. 44, no. 4, pp. 379$388,2010$.

[77] S. Movafagh, S. Crook, and K. Vo, "Regulation of hypoxiainducible Factor-1a by reactive oxygen species: new developments in an old debate," Journal of Cellular Biochemistry, vol. 116, no. 5, pp. 696-703, 2015.

[78] S. Cannito, E. Novo, A. Compagnone et al., "Redox mechanisms switch on hypoxia- dependent epithelial-mesenchymal transition in cancer cells," Carcinogenesis, vol. 29, no. 12, pp. 22672278, 2008.

[79] J. E. Klaunig, L. M. Kamendulis, and B. A. Hocevar, "Oxidative stress and oxidative damage in carcinogenesis," Toxicologic Pathology, vol. 38, no. 1, pp. 96-109, 2010.

[80] L. Zuo, B. A. Rose, W. J. Roberts, F. He, and A. K. BanesBerceli, "Molecular characterization of reactive oxygen species in systemicand pulmonary hypertension," American Journal of Hypertension, vol. 27, no. 5, pp. 643-650, 2014.

[81] Y. Lavrovsky, B. Chatterjee, R. A. Clark, and A. K. Roy, "Role of redox-regulated transcription factors in inflammation, aging and age-related diseases," Experimental Gerontology, vol. 35, no. 5, pp. 521-532, 2000.

[82] S. Coso, I. Harrison, C. B. Harrison et al., "NADPH oxidases as regulators of tumor angiogenesis: current and emerging concepts," Antioxidants and Redox Signaling, vol. 16, no. 11, pp. 1229-1247, 2012.

[83] M. Maryanovich and A. Gross, "A ROS rheostat for cell fate regulation," Trends in Cell Biology, vol. 23, no. 3, pp. 129-134, 2013.

[84] R. Liang and S. Ghaffari, "Stem cells, redox signaling, and stem cell aging," Antioxidants \& Redox Signaling, vol. 20, no. 12, pp. 1902-1916, 2014.

[85] M. Scheibye-Knudsen, E. F. Fang, D. L. Croteau, D. M. Wilson, and V. A. Bohr, "Protecting the mitochondrial powerhouse," Trends in Cell Biology, vol. 25, no. 3, pp. 158-170, 2015.

[86] S. J. Dixon and B. R. Stockwell, "The role of iron and reactive oxygen species in cell death," Nature Chemical Biology, vol. 10, no. 1, pp. 9-17, 2014.
[87] G. Filomeni, D. De Zio, and F. Cecconi, "Oxidative stress and autophagy: the clash between damage and metabolic needs," Cell Death and Differentiation, vol. 22, no. 3, pp. 377-388, 2015.

[88] Y. Lei, K. Wang, L. Deng, Y. Chen, E. C. Nice, and C. Huang, "Redox regulation of inflammation: old elements, a new story," Medicinal Research Reviews, vol. 35, no. 2, pp. 306-340, 2015.

[89] J. M. Abais, M. Xia, Y. Zhang, K. M. Boini, and P.-L. Li, "Redox regulation of NLRP3 inflammasomes: ROS as trigger or effector?" Antioxidants and Redox Signaling, vol. 22, no. 13, pp. 1111-1129, 2015.

[90] J. Cachat, C. Deffert, S. Hugues, and K.-H. Krause, "Phagocyte NADPH oxidase and specific immunity," Clinical Science, vol. 128, no. 10, pp. 635-648, 2015.

[91] U. Weyemi and C. Dupuy, "The emerging role of ROSgenerating NADPH oxidase NOX4 in DNA-damage responses," Mutation Research/Reviews in Mutation Research, vol. 751, no. 2, pp. 77-81, 2012.

[92] S. W. Kang, S. Lee, and E. K. Lee, "ROS and energy metabolism in cancer cells: alliance for fast growth," Archives of Pharmacal Research, vol. 38, no. 3, pp. 338-345, 2015.

[93] W.-S. Wu, "The signaling mechanism of ROS in tumor progression," Cancer and Metastasis Reviews, vol. 25, no. 4, pp. 695-705, 2006.

[94] S. Reuter, S. C. Gupta, M. M. Chaturvedi, and B. B. Aggarwal, "Oxidative stress, inflammation, and cancer: how are they linked?” Free Radical Biology and Medicine, vol. 49, no. 11, pp. 1603-1616, 2010.

[95] P. Davalli, F. Rizzi, A. Caporali et al., "Anticancer activity of green tea polyphenols in prostate gland," Oxidative Medicine and Cellular Longevity, vol. 2012, Article ID 984219, 18 pages, 2012.

[96] M. Assuncao and J. P. Andrade, "Protective action of green tea catechins in neuronal mitochondria during aging," Frontiers in Bioscience, vol. 20, no. 2, pp. 247-262, 2015.

[97] C. López-Otín, M. A. Blasco, L. Partridge, M. Serrano, and G. Kroemer, "The hallmarks of aging," Cell, vol. 153, no. 6, pp. 11941217, 2013.

[98] C. C. Benz and C. Yau, "Ageing, oxidative stress and cancer: paradigms in parallax," Nature Reviews Cancer, vol. 8, no. 11, pp. 875-879, 2008.

[99] F. Bonomini, L. F. Rodella, and R. Rezzani, "Metabolic syndrome, aging and involvement of oxidative stress," Aging and Disease, vol. 6, no. 2, pp. 109-120, 2015.

[100] J. E. Martin and M. T. Sheaff, "The pathology of ageing: concepts and mechanisms," The Journal of Pathology, vol. 211, no. 2, pp. 111-113, 2007.

[101] A. K. Biala, R. Dhingra, and L. A. Kirshenbaum, "Mitochondrial dynamics: orchestrating the journey to advanced age," Journal of Molecular and Cellular Cardiology, vol. 83, pp. 37-43, 2015.

[102] A. Bratic and N.-G. Larsson, "The role of mitochondria in aging," The Journal of Clinical Investigation, vol. 123, no. 3, pp. 951-957, 2013.

[103] H. P. Indo, H.-C. Yen, I. Nakanishi et al., "A mitochondrial superoxide theory for oxidative stress diseases and aging," Journal of Clinical Biochemistry and Nutrition, vol. 56, no. 1, pp. 1-7, 2015.

[104] M. L. Genova and G. Lenaz, "The interplay between respiratory supercomplexes and ros in aging," Antioxidants \& Redox Signaling, vol. 23, no. 3, pp. 208-238, 2015.

[105] G. Barja, "The mitochondrial free radical theory of aging," Progress in Molecular Biology and Translational Science, vol. 127, pp. 1-27, 2014. 
[106] G. López-Lluch, C. Santos-Ocaña, J. A. Sánchez-Alcázar et al., "Mitochondrial responsibility in ageing process: innocent, suspect or guilty," Biogerontology, vol. 16, no. 5, pp. 599-620, 2015.

[107] L. Fontana and L. Partridge, "Promoting health and longevity through diet: from model organisms to humans," Cell, vol. 161, no. 1, pp. 106-118, 2015.

[108] M. A. Bouzid, E. Filaire, A. McCall, and C. Fabre, "Radical oxygen species, exercise and aging: an update," Sports Medicine, vol. 45, no. 9, pp. 1245-1261, 2015.

[109] Y. Zhang, Y. Ikeno, W. Qi et al., "Mice deficient in both Mn superoxide dismutase and glutathione peroxidase-1 have increased oxidative damage and a greater incidence of pathology but no reduction in longevity," The Journals of Gerontology Series A: Biological Sciences and Medical Sciences, vol. 64, no. 12, pp. 1212-1220, 2009.

[110] M. J. Kwon, K. Y. Lee, H.-W. Lee, J.-H. Kim, and T.-Y. Kim, "SOD3 variant R213G altered SOD3 function, leading to ROS mediated inflammation and damage in multiple organs of premature aging mice," Antioxidants \& Redox Signaling, vol. 23, no. 12, pp. 985-999, 2015.

[111] Y. H. Edrey and A. B. Salmon, "Revisiting an age-old question regarding oxidative stress," Free Radical Biology and Medicine, vol. 71, pp. 368-378, 2014.

[112] C. E. Schaar, D. J. Dues, K. K. Spielbauer et al., "Mitochondrial and cytoplasmic ROS have opposing effects on lifespan," PLoS Genetics, vol. 1, no. 2, Article ID e1004972, 2015.

[113] G. M. Cunningham, M. G. Roman, L. C. Flores et al., "The paradoxical role of thioredoxin on oxidative stress and aging," Archives of Biochemistry and Biophysics, vol. 576, pp. 32-38, 2015.

[114] G. Bjelakovic, D. Nikolova, and C. Gluud, "Antioxidant supplements and mortality," Current Opinion in Clinical Nutrition and Metabolic Care, vol. 17, no. 1, pp. 40-44, 2014.

[115] M. Breitenbach, M. Rinnerthaler, J. Hartl et al., "Mitochondria in ageing: there is metabolism beyond the ROS," FEMS Yeast Research, vol. 14, no. 1, pp. 198-212, 2014.

[116] M. Lagouge and N.-G. Larsson, "The role of mitochondrial DNA mutations and free radicals in disease and ageing," Journal of Internal Medicine, vol. 273, no. 6, pp. 529-543, 2013.

[117] C. Bertram and R. Hass, "Cellular responses to reactive oxygen species-induced DNA damage and aging," Biological Chemistry, vol. 389 , no. 3, pp. 211-220, 2008.

[118] C. Fimognari, "Role of oxidative RNA damage in chronicdegenerative diseases," Oxidative Medicine and Cellular Longevity, vol. 2015, Article ID 358713, 8 pages, 2015.

[119] T. Shimi and R. D. Goldman, "Nuclear lamins and oxidative stress in cell proliferation and longevity," Advances in Experimental Medicine and Biology, vol. 773, pp. 415-430, 2014.

[120] M. Rinnerthaler, J. Bischof, M. K. Streubel, A. Trost, and K. Richter, "Oxidative stress in aging human skin," Biomolecules, vol. 5, no. 2, pp. 545-589, 2015.

[121] L.-J. Yan, "Positive oxidative stress in aging and aging-related disease tolerance," Redox Biology, vol. 2, pp. 165-169, 2014.

[122] M. Szyf, "Nongenetic inheritance and transgenerational epigenetics," Trends in Molecular Medicine, vol. 21, no. 2, pp. 134-144, 2015.

[123] B. Jin, Y. Li, and K. D. Robertson, "DNA methylation: superior or subordinate in the epigenetic hierarchy?" Genes \& Cancer, vol. 2, no. 6, pp. 607-617, 2011.

[124] C. A. Hamm and F. F. Costa, "Epigenomes as therapeutic targets," Pharmacology and Therapeutics, vol. 151, pp. 72-86, 2015.
[125] P. D’Aquila, D. Bellizzi, and G. Passarino, "Mitochondria in health, aging and diseases: the epigenetic perspective," Biogerontology, vol. 16, no. 5, pp. 569-585, 2015.

[126] D. T. Shaughnessy, K. McAllister, L. Worth et al., "Mitochondria, energetics, epigenetics, and cellular responses to stress," Environmental Health Perspectives, vol. 122, no. 12, pp. 1271-1278, 2015.

[127] C. Podrini, M. Borghesan, A. Greco, V. Pazienza, G. Mazzoccoli, and M. Vinciguerra, "Redox homeostasis and epigenetics in non-alcoholic fatty liver disease (NAFLD)," Current Pharmaceutical Design, vol. 19, no. 15, pp. 2737-2746, 2013.

[128] I. Afanas'ev, "New nucleophilic mechanisms of ros-dependent epigenetic modifications: comparison of aging and cancer," Aging, vol. 5, no. 1, pp. 52-62, 2014.

[129] H. Tamaru, "Confining euchromatin/heterochromatin territory: Jumonji crosses the line," Genes \& Development, vol. 24, no. 14 , pp. 1465-1478, 2010.

[130] A. Siomek, D. Gackowski, A. Szpila et al., "Epigenetic modifications and NF- $\kappa \mathrm{B}$ pathway activity in $\mathrm{Cu}, \mathrm{Zn}$-SOD-deficient mice," Molecular and Cellular Biochemistry, vol. 397, no. 1-2, pp. 187-194, 2014.

[131] L. J. Kroese and P. G. Scheffer, "8-hydroxy-2'-deoxyguanosine and cardiovascular disease: a systematic review," Current Atherosclerosis Reports, vol. 16, no. 11, p. 452, 2014.

[132] W. Wongpaiboonwattana, P. Tosukhowong, T. Dissayabutra, A. Mutirangura, and C. Boonla, "Oxidative stress induces hypomethylation of LINE-1 and hypermethylation of the RUNX3 promoter in a bladder cancer cell line," Asian Pacific Journal of Cancer Prevention, vol. 14, no. 6, pp. 3773-3778, 2013.

[133] Y. Wang, W. Wu, C. Yao et al., "Elevated tissue Cr levels, increased plasma oxidative markers, and global hypomethylation of blood DNA in male Sprague-Dawley rats exposed to potassium dichromate indrinking water," Environmental Toxicology, 2015.

[134] A. J. Patterson, D. Xiao, F. Xiong, B. Dixon, and L. Zhang, "Hypoxia-derived oxidative stress mediates epigenetic repression of PKC $\varepsilon$ gene in foetal rat hearts," Cardiovascular Research, vol. 93, no. 2, pp. 302-310, 2012.

[135] D. Ben-Avraham, R. H. Muzumdar, and G. Atzmon, "Epigenetic genome-wide association methylation in aging and longevity," Epigenomics, vol. 4, no. 5, pp. 503-509, 2012.

[136] M. Zampieri, F. Ciccarone, R. Calabrese, C. Franceschi, A. Bürkle, and P. Caiafa, "Reconfiguration of DNA methylation in aging," Mechanisms of Ageing and Development, vol. 151, pp. 6070, 2015.

[137] S. D. van Otterdijk, J. C. Mathers, and G. Strathdee, "Do agerelated changes in DNA methylation play a role in the development of age-related diseases?" Biochemical Society Transactions, vol. 41, no. 3, pp. 803-807, 2013.

[138] J. Y. Min, S.-O. Lim, and G. Jung, "Downregulation of catalase by reactive oxygen species via hypermethylation of $\mathrm{CpG}$ island II on the catalase promoter," FEBS Letters, vol. 584, no. 11, pp. 2427-2432, 2010.

[139] Q. Wu and X. Ni, "ROS-mediated DNA methylation pattern alterations in carcinogenesis," Current Drug Targets, vol. 16, no. 1, pp. 13-19, 2015.

[140] D. Ziech, R. Franco, A. Pappa, and M. I. Panayiotidis, "Reactive Oxygen Species (ROS) - induced genetic and epigenetic alterations in human carcinogenesis," Mutation Research, vol. 711, no. 1-2, pp. 167-173, 2011. 
[141] M. Venza, M. Visalli, C. Beninati, G. V. De Gaetano, D. Teti, and I. Venza, "Cellular mechanisms of oxidative stress and action in melanoma," Oxidative Medicine and Cellular Longevity, vol. 2015, Article ID 481782, 11 pages, 2015.

[142] S. L. Archer, G. Marsboom, G. H. Kim et al., "Epigenetic attenuation of mitochondrial superoxide dismutase 2 in pulmonary arterial hypertension: a basis for excessive cell proliferation and a new therapeutic target," Circulation, vol. 121, no. 24, pp. 26612671, 2010.

[143] V. Iacobazzi, A. Castegna, V. Infantino, and G. Andria, "Mitochondrial DNA methylation as a next-generation biomarker and diagnostic tool," Molecular Genetics and Metabolism, vol. 110, no. 1-2, pp. 25-34, 2013.

[144] J. H. Santos, J. N. Meyer, M. Skorvaga, L. A. Annab, and B. Van Houten, "Mitochondrial hTERT exacerbates free-radicalmediated mtDNA damage," Aging Cell, vol. 3, no. 6, pp. 399-411, 2004.

[145] I. R. Indran, M. P. Hande, and S. Pervaiz, "hTERT overexpression alleviates intracellular ROS production, improves mitochondrial function, and inhibits ROS-mediated apoptosis in cancer cells," Cancer Research, vol. 71, no. 1, pp. 266-276, 2011.

[146] C. Cencioni, F. Spallotta, F. Martelli et al., "Oxidative stress and epigenetic regulation in ageing and age-related diseases," International Journal of Molecular Sciences, vol. 14, no. 9, pp. 17643-17663, 2013.

[147] F. J. Rang and J. Boonstra, "Causes and consequences of agerelated changes in DNA methylation: a role for ROS?" Biology, vol. 3, no. 2, pp. 403-425, 2014.

[148] J. Nanduri, V. Makarenko, V. D. Reddy et al., "Epigenetic regulation of hypoxic sensing disrupts cardiorespiratory homeostasis," Proceedings of the National Academy of Sciences of the United States of America, vol. 109, no. 7, pp. 2515-2520, 2012.

[149] N. H. Zawia, D. K. Lahiri, and F. Cardozo-Pelaez, "Epigenetics, oxidative stress, and Alzheimer disease," Free Radical Biology and Medicine, vol. 46, no. 9, pp. 1241-1249, 2009.

[150] A. Lechel, A. Satyanarayana, Z. Ju et al., "The cellular level of telomere dysfunction determines induction of senescence or apoptosis in vivo," EMBO Reports, vol. 6, no. 3, pp. 275-281, 2005.

[151] D. V. Ziegler, C. D. Wiley, and M. C. Velarde, "Mitochondrial effectors of cellular senescence: beyond the free radical theory of aging," Aging Cell, vol. 14, no. 1, pp. 1-7, 2015.

[152] Y. Y. Sanders, H. Liu, X. Zhang et al., "Histone modifications in senescence-associated resistance to apoptosis by oxidative stress," Redox Biology, vol. 1, no. 1, pp. 8-16, 2013.

[153] K. Tominaga, "The emerging role of senescent cells in tissue homeostasis and pathophysiology," Pathobiology of Aging \& Age-Related Diseases, vol. 5, Article ID 27743, 2015.

[154] J. Wagner, N. Damaschke, B. Yang et al., "Overexpression of the novel senescence marker $\beta$-galactosidase (GLB1) in prostate cancer predicts reduced PSA recurrence," PLOS ONE, vol. 10, no. 4, Article ID e0124366, 2015.

[155] R.-M. Laberge, Y. Sun, A. V. Orjalo et al., "MTOR regulates the pro-tumorigenic senescence-associated secretory phenotype by promoting IL1A translation," Nature Cell Biology, vol. 17, no. 8, pp. 1049-1061, 2015.

[156] J. F. Passos, G. Nelson, C. Wang et al., "Feedback between p21 and reactive oxygen production is necessary for cell senescence," Molecular Systems Biology, vol. 6, article 347, 2010.

[157] C. Lawless, D. Jurk, C. S. Gillespie et al., "A stochastic step model of replicative senescence explains ROS production rate in ageing cell populations," PLoS ONE, vol. 7, no. 2, Article ID e32117, 2012.

[158] E. K. Ahmed, A. Rogowska-Wrzesinska, P. Roepstorff, A.-L. Bulteau, and B. Friguet, "Protein modification and replicative senescence of WI-38 human embryonic fibroblasts," Aging Cell, vol. 9, no. 2, pp. 252-272, 2010.

[159] A. Lauri, G. Pompilio, and M. C. Capogrossi, "The mitochondrial genome in aging and senescence," Ageing Research Reviews, vol. 18, pp. 1-15, 2014.

[160] A. Vigneron and K. H. Vousden, "p53, ROS and senescence in the control of aging," Aging, vol. 2, no. 8, pp. 471-474, 2010.

[161] A. Freund, C. K. Patil, and J. Campisi, "p38MAPK is a novel DNA damage response independent regulator of the senescence-associated secretory phenotype," The EMBO Journal, vol. 30, no. 8, pp. 1536-1548, 2011.

[162] M. Geiszt, J. B. Kopp, P. Várnai, and T. L. Leto, "Identification of Renox, an NAD $(\mathrm{P}) \mathrm{H}$ oxidase in kidney," Proceedings of the National Academy of Sciences of the United States of America, vol. 97, no. 14, pp. 8010-8014, 2000.

[163] D. J. Baker, T. Wijshake, T. Tchkonia et al., "Clearance of p16 Ink4a-positive senescent cells delays ageing-associated disorders," Nature, vol. 479, no. 7372, pp. 232-236, 2011.

[164] J.-P. Coppé, P.-Y. Desprez, A. Krtolica, and J. Campisi, “The senescence-associated secretory phenotype: the dark side of tumor suppression," Annual Review of Pathology: Mechanisms of Disease, vol. 5, pp. 99-118, 2010.

[165] Z. Feng, M. Lin, and R. Wu, "The regulation of aging and longevity: a new and complex role of p53," Genes \& Cancer, vol. 2, no. 4, pp. 443-452, 2011.

[166] A. Rufini, P. Tucci, I. Celardo, and G. Melino, "Senescence and aging: the critical roles of p53," Oncogene, vol. 32, no. 43, pp. 5129-5143, 2013.

[167] J. C. Jeyapalan and J. M. Sedivy, "Cellular senescence and organismal aging," Mechanisms of Ageing and Development, vol. 129, no. 7-8, pp. 467-474, 2008.

[168] H.-O. Byun, Y.-K. Lee, J.-M. Kim, and G. Yoon, "From cell senescence to age-related diseases: differential mechanisms of action of senescence-associated secretory phenotypes," $B M B$ Reports, vol. 48, no. 10, pp. 549-558, 2015.

[169] R. M. Naylor, D. J. Baker, and J. M. van Deursen, "Senescent cells: a novel therapeutic target for aging and age-related diseases," Clinical Pharmacology and Therapeutics, vol. 93, no. 1, pp. 105-116, 2013.

[170] L. M. Holdt, K. Sass, G. Gäbel, H. Bergert, J. Thiery, and D. Teupser, "Expression of Chr9p21 genes CDKN2B (p15INK4b), CDKN2A (p16INK4a, p14ARF) and MTAP in human atherosclerotic plaque," Atherosclerosis, vol. 214, no. 2, pp. 264-270, 2011.

[171] J. C. Wang and M. Bennett, "Aging and atherosclerosis: mechanisms, functional consequences, and potential therapeutics for cellular senescence," Circulation Research, vol. 111, no. 2, pp. 245-259, 2012.

[172] R. S. Roberson, S. J. Kussick, E. Vallieres, S.-Y. J. Chen, and D. Y. $\mathrm{Wu}$, "Escape from therapy-induced accelerated cellular senescence in p53-null lung cancer cells and in human lung cancers," Cancer Research, vol. 65, no. 7, pp. 2795-2803, 2005.

[173] T. Fernández-Marcelo, A. Gómez, I. Pascua et al., "Telomere length and telomerase activity in non-small cell lung cancer prognosis: clinical usefulness of a specific telomere status," Journal of Experimental and Clinical Cancer Research, vol. 34, no. 1, article 78, 2015. 
[174] C. Thangavel, J. L. Dean, A. Ertel et al., "Therapeutically activating RB: reestablishing cell cycle control in endocrine therapyresistant breast cancer," Endocrine-Related Cancer, vol. 18, no. 3, pp. 333-345, 2011.

[175] M. Althubiti, L. Lezina, S. Carrera et al., "Characterization of novel markers of senescence and their prognostic potential in cancer," Cell Death and Disease, vol. 5, no. 11, Article ID e1528, 2014.

[176] J. A. Rader, M. R. Russell, L. S. Hart et al., "Dual CDK4/CDK6 inhibition induces cell-cycle arrest and senescence in neuroblastoma," Clinical Cancer Research, vol. 19, no. 22, pp. 6173-6182, 2013.

[177] A. Tsugu, K. Sakai, P. B. Dirks et al., "Expression of p57(KIP2) potently blocks the growth of human astrocytomas and induces cell senescence," The American Journal of Pathology, vol. 157, no. 3, pp. 919-932, 2000.

[178] R. Sidi, G. Pasello, I. Opitz et al., "Induction of senescence markers after neo-adjuvant chemotherapy of malignant pleural mesothelioma and association with clinical outcome: an exploratory analysis," European Journal of Cancer, vol. 47, no. 2, pp. 326-332, 2011.

[179] V. C. Gray-Schopfer, S. C. Cheong, H. Chong et al., "Cellular senescence in naevi and immortalisation in melanoma: a role for p16?" British Journal of Cancer, vol. 95, no. 4, pp. 496-505, 2006.

[180] J. A. Ewald, J. A. Desotelle, D. R. Church et al., "Androgen deprivation induces senescence characteristics in prostate cancer cells in vitro and in vivo," The Prostate, vol. 73, no. 4, pp. 337-345, 2013.

[181] V. Paradis, N. Youssef, D. Dargère et al., "Replicative senescence in normal liver, chronic hepatitis $\mathrm{C}$, and hepatocellular carcinomas," Human Pathology, vol. 32, no. 3, pp. 327-332, 2001.

[182] T. Fernndez-Marcelo, A. Morn, C. de Juan et al., "Differential expression of senescence and cell death factors in non-small cell lung and colorectal tumors showing telomere attrition," Oncology, vol. 82, no. 3, pp. 153-164, 2012.

[183] G. J. Allan, J. Beattie, and D. J. Flint, "Epithelial injury induces an innate repair mechanism linked to cellular senescence and fibrosis involving IGF-binding protein-5," Journal of Endocrinology, vol. 199, no. 2, pp. 155-164, 2008.

[184] H. Yanai, A. Shteinberg, Z. Porat et al., "Cellular senescence-like features of lung fibroblasts derived from idiopathic pulmonary fibrosis patients," Aging, vol. 7, no. 9, pp. 664-672, 2015.

[185] B. M. Fischer, J. K. Wong, S. Degan et al., "Increased expression of senescence markers in cystic fibrosis airways," American Journal of Physiology - Lung Cellular and Molecular Physiology, vol. 304, no. 6, pp. L394-L400, 2013.

[186] P. M. Tachtatzis, A. Marshall, A. Aravinthan et al., "Chronic hepatitis B virus infection: the relation between hepatitis B antigen expression, telomere length, senescence, inflammation and fibrosis," PLoS ONE, vol. 10, no. 5, Article ID e0127511, 2015.

[187] D. Portilla, "Apoptosis, fibrosis and senescence," NephronClinical Practice, vol. 127, no. 1-4, pp. 65-69, 2014.

[188] M. Naesens, "Replicative senescence in kidney aging, renal disease, and renal transplantation," Discovery Medicine, vol. 11, no. 56, pp. 65-75, 2011.

[189] R. Bhat, E. P. Crowe, A. Bitto et al., "Astrocyte senescence as a component of Alzheimer's disease," PLoS ONE, vol. 7, no. 9, Article ID e45069, 2012.

[190] A. Salminen, J. Ojala, K. Kaarniranta, A. Haapasalo, M. Hiltunen, and H. A. Soininen, "Astrocytes in the aging brain express characteristics of senescence-associated secretory phenotype," European Journal of Neuroscience, vol. 34, no. 1, pp. 311, 2011.

[191] J. Birch, R. K. Anderson, C. Correia-Melo et al., "DNA damage response at telomeres contributes to lung ageing and chronic obstructive pulmonary disease," American Journal of Physiology_Lung Cellular and Molecular Physiology, vol. 309, no. 10, pp. L1124-L1137, 2015.

[192] S. Adnot, V. Amsellem, L. Boyer et al., “Telomere dysfunction and cell senescence in chronic lung diseases: therapeutic potential," Pharmacology \& Therapeutics, vol. 153, pp. 125-134, 2015.

[193] H. Noureddine, G. Gary-Bobo, M. Alifano et al., "Pulmonary artery smooth muscle cell senescence is a pathogenic mechanism for pulmonary hypertension in chronic lung disease," Circulation Research, vol. 109, no. 5, pp. 543-553, 2011.

[194] T. Tsuji, K. Aoshiba, and A. Nagai, "Alveolar cell senescence in patients with pulmonary emphysema," American Journal of Respiratory and Critical Care Medicine, vol. 174, no. 8, pp. 886893, 2006.

[195] J. K. Alder, N. Guo, F. Kembou et al., "Telomere length is a determinant of emphysema susceptibility," American Journal of Respiratory and Critical Care Medicine, vol. 184, no. 8, pp. 904912, 2011.

[196] J. Choi, I. Shendrik, M. Peacocke et al., "Expression of senescence-associated beta-galactosidase in enlarged prostates from men with benign prostatic hyperplasia," Urology, vol. 56, no. 1, pp. 160-166, 2000.

[197] P. Castro, C. Xia, L. Gomez, D. J. Lamb, and M. Ittmann, "Interleukin-8 expression is increased in senescent prostatic epithelial cells and promotes the development of benign prostatic hyperplasia," Prostate, vol. 60, no. 2, pp. 153-159, 2004.

[198] H. Zou, E. Stoppani, D. Volonte, and F. Galbiati, "Caveolin1, cellular senescence and age-related diseases," Mechanisms of Ageing and Development, vol. 132, no. 11-12, pp. 533-542, 2011.

[199] D. Muñoz-Espín and M. Serrano, "Cellular senescence: from physiology to pathology," Nature Reviews Molecular Cell Biology, vol. 15, no. 7, pp. 482-496, 2014.

[200] M. V. Blagosklonny, "Prospective treatment of age-related diseases by slowing down aging," The American Journal of Pathology, vol. 181, no. 4, pp. 1142-1146, 2012.

[201] M. Collado and M. Serrano, "Senescence in tumours: evidence from mice and humans," Nature Reviews Cancer, vol. 10, no. 1, pp. 51-57, 2010.

[202] A. S. L. Chan, S. N. Mowla, P. Arora, and P. S. Jat, "Tumour suppressors and cellular senescence," IUBMB Life, vol. 66, no. 12, pp. 812-822, 2014.

[203] I. Badiola, F. Santaolalla, P. Garcia-Gallastegui, S.-D. R. Ana, F. Unda, and G. Ibarretxe, "Biomolecular bases of the senescence process and cancer. A new approach to oncological treatment linked to ageing," Ageing Research Reviews B, vol. 23, pp. 125138, 2015.

[204] P. Yaswen, K. L. MacKenzie, W. N. Keith et al., "Therapeutic targeting of replicative immortality," Seminars in Cancer Biology, vol. 35, pp. S104-S128, 2015.

[205] G. Taormina and M. G. Mirisola, "Longevity: epigenetic and biomolecular aspects," Biomolecular Concepts, vol. 6, no. 2, pp. 105-117, 2015.

[206] H. A. Cruickshanks, T. McBryan, D. M. Nelson et al., "Senescent cells harbour features of the cancer epigenome," Nature Cell Biology, vol. 15, no. 12, pp. 1495-1506, 2013. 
[207] R. Cao, L. Wang, H. Wang et al., "Role of histone H3 lysine 27 methylation in polycomb-group silencing," Science, vol. 298, no. 5595, pp. 1039-1043, 2002.

[208] P. A. C. Cloos, J. Christensen, K. Agger, and K. Helin, "Erasing the methyl mark: histone demethylases at the center of cellular differentiation and disease," Genes \& Development, vol. 22, no. 9, pp. 1115-1140, 2008.

[209] M. De Cecco, S. W. Criscione, E. J. Peckham et al., "Genomes of replicatively senescent cells undergo global epigenetic changes leading to gene silencing and activation of transposable elements," Aging Cell, vol. 12, no. 2, pp. 247-256, 2013.

[210] A. Scelfo, A. Piunti, and D. Pasini, "The controversial role of the Polycomb group proteins in transcription and cancer: how much do we not understand Polycomb proteins?" The FEBS Journal, vol. 282, no. 9, pp. 1703-1722, 2015.

[211] D. Pasini, P. A. C. Cloos, J. Walfridsson et al., "JARID2 regulates binding of the Polycomb repressive complex 2 to target genes in ES cells," Nature, vol. 464, no. 7286, pp. 306-310, 2010.

[212] N. Martin, S. Raguz, G. Dharmalingam, and J. Gil, "Co-regulation of senescence-associated genes by oncogenic homeobox proteins and polycomb repressive complexes," Cell Cycle, vol. 12, no. 14, pp. 2194-2199, 2013.

[213] P. K. Puvvula, R. D. Desetty, P. Pineau et al., "Long noncoding RNA PANDA and scaffold-attachment-factor SAFA control senescence entry and exit," Nature Communications, vol. 5, article 5323, 2014.

[214] R. J. Klose, E. M. Kallin, and Y. Zhang, "JmjC-domain-containing proteins and histone demethylation," Nature Reviews Genetics, vol. 7, no. 9, pp. 715-727, 2006.

[215] K. Agger, P. A. C. Cloos, L. Rudkjær et al., "The H3K27me3 demethylase JMJD3 contributes to the activation of the INK4AARF locus in response to oncogene- and stress-induced senescence," Genes \& Development, vol. 23, no. 10, pp. 1171-1176, 2009.

[216] M. Barradas, E. Anderton, J. C. Acosta et al., "Histone demethylase JMJD3 contributes to epigenetic control of INK4a/ARF by oncogenic RAS," Genes \& Development, vol. 23, no. 10, pp. 1177$1182,2009$.

[217] P. M. Perrigue, M. E. Silva, C. D. Warden et al., "The histone demethylase Jumonji coordinates cellular senescence including secretion of neural stem cell-attracting cytokines," Molecular Cancer Research, vol. 13, no. 4, pp. 636-650, 2015.

[218] S. Djebali, C. A. Davis, A. Merkel et al., "Landscape of transcription in human cells," Nature, vol. 489, no. 7414, pp. 101-108, 2012.

[219] J. T. Y. Kung, D. Colognori, and J. T. Lee, "Long noncoding RNAs: past, present, and future," Genetics, vol. 193, no. 3, pp. 651-669, 2013.

[220] D. P. Bartel, "MicroRNAs: target recognition and regulatory functions," Cell, vol. 136, no. 2, pp. 215-233, 2009.

[221] S. Dimmeler and P. Nicotera, "MicroRNAs in age-related diseases," EMBO Molecular Medicine, vol. 5, no. 2, pp. 180-190, 2013.

[222] S. Greco, M. Gorospe, and F. Martelli, "Noncoding RNA in age-related cardiovascular diseases," Journal of Molecular and Cellular Cardiology, vol. 83, pp. 142-155, 2015.

[223] L. Li and H. Y. Chang, "Physiological roles of long noncoding RNAs: insight from knockout mice," Trends in Cell Biology, vol. 24, no. 10, pp. 594-602, 2014.

[224] K. Abdelmohsen, A. Panda, M.-J. Kang et al., "Senescence-associated lncRNAs: senescence-associated long noncoding RNAs," Aging Cell, vol. 12, no. 5, pp. 890-900, 2013.
[225] V. Tripathi, Z. Shen, A. Chakraborty et al., "Long noncoding RNA MALAT1 controls cell cycle progression by regulating the expression of oncogenic transcription factor B-MYB," PLoS Genetics, vol. 9, no. 3, Article ID e1003368, 2013.

[226] K. Abdelmohsen, A. C. Panda, M. Kang et al., "7SL RNA represses 53 translation by competing with HuR," Nucleic Acids Research, vol. 42, no. 15, pp. 10099-10111, 2014.

[227] J. Nie, C. Peng, W. Pei et al., "A novel role of long non-coding RNAs in response to X-ray irradiation," Toxicology In Vitro, vol. 30, no. 1, pp. 536-544, 2015.

[228] V. Bianchessi, I. Badi, M. Bertolotti et al., "The mitochondrial lncRNA ASncmtRNA-2 is induced in aging and replicative senescence in Endothelial Cells," Journal of Molecular and Cellular Cardiology, vol. 81, pp. 62-70, 2015.

[229] J. J. Cassidy, A. R. Jha, D. M. Posadas et al., "MiR-9a minimizes the phenotypic impact of genomic diversity by buffering a transcription factor," Cell, vol. 155, no. 7, pp. 1556-1567, 2013.

[230] M. Takahashi, A. Eda, T. Fukushima, and H. Hohjoh, "Reduction of type IV collagen by upregulated miR-29 in normal elderly mouse and klotho-deficient, senescence-model mouse," PloS ONE, vol. 7, no. 11, Article ID e48974, 2012.

[231] M. Kato, X. Chen, S. Inukai, H. Zhao, and F. J. Slack, "Ageassociated changes in expression of small, noncoding RNAs, including microRNAs, in C. elegans," $R N A$, vol. 17, no. 10, pp. 1804-1820, 2011.

[232] N. Liu, M. Landreh, K. Cao et al., "The microRNA miR34 modulates ageing and neurodegeneration in Drosophila," Nature, vol. 482, no. 7386, pp. 519-523, 2012.

[233] R. Zhang, Q. Zhang, J. Niu et al., "Screening of microRNAs associated with Alzheimer's disease using oxidative stress cell model and different strains of senescence accelerated mice," Journal of the Neurological Sciences, vol. 338, no. 1-2, pp. 57-64, 2014.

[234] E. Miñones-Moyano, S. Porta, G. Escaramís et al., "MicroRNA profiling of Parkinson's disease brains identifies early downregulation of miR-34b/c which modulate mitochondrial function," Human Molecular Genetics, vol. 20, no. 15, pp. 3067-3078, 2011.

[235] P. M. Gaughwin, M. Ciesla, N. Lahiri, S. J. Tabrizi, P. Brundin, and M. Björkqvist, "Hsa-miR-34b is a plasma-stable microRNA that is elevated in pre-manifest Huntington's disease," Human Molecular Genetics, vol. 20, no. 11, Article ID ddr111, pp. 22252237, 2011.

[236] A. Magenta, C. Cencioni, P. Fasanaro et al., "miR-200c is upregulated by oxidative stress and induces endothelial cell apoptosis and senescence via ZEB1 inhibition," Cell Death and Differentiation, vol. 18, no. 10, pp. 1628-1639, 2011. 


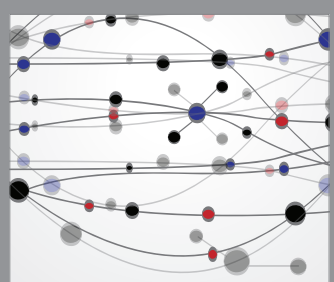

The Scientific World Journal
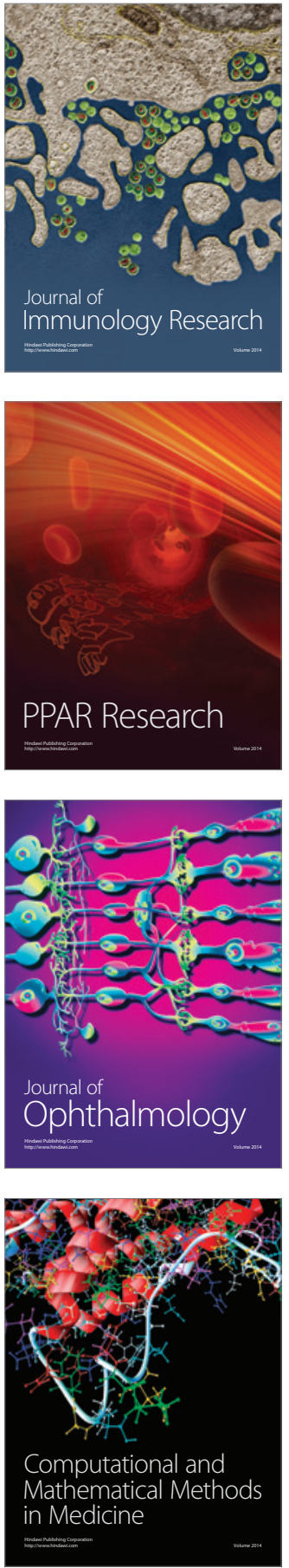

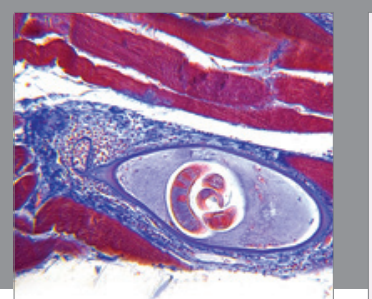

Gastroenterology Research and Practice

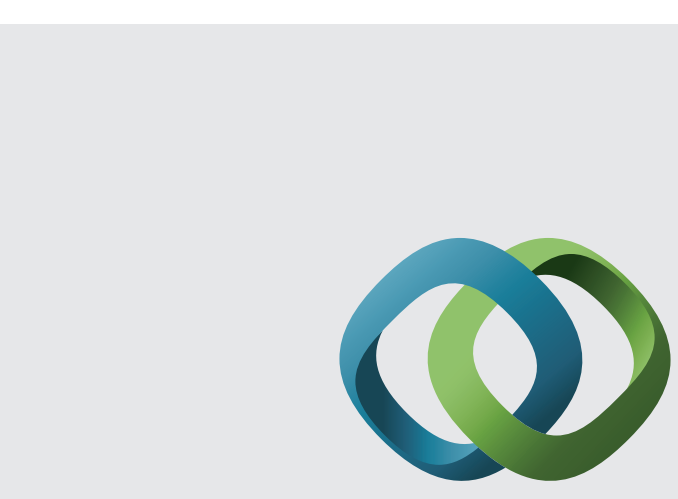

\section{Hindawi}

Submit your manuscripts at

http://www.hindawi.com
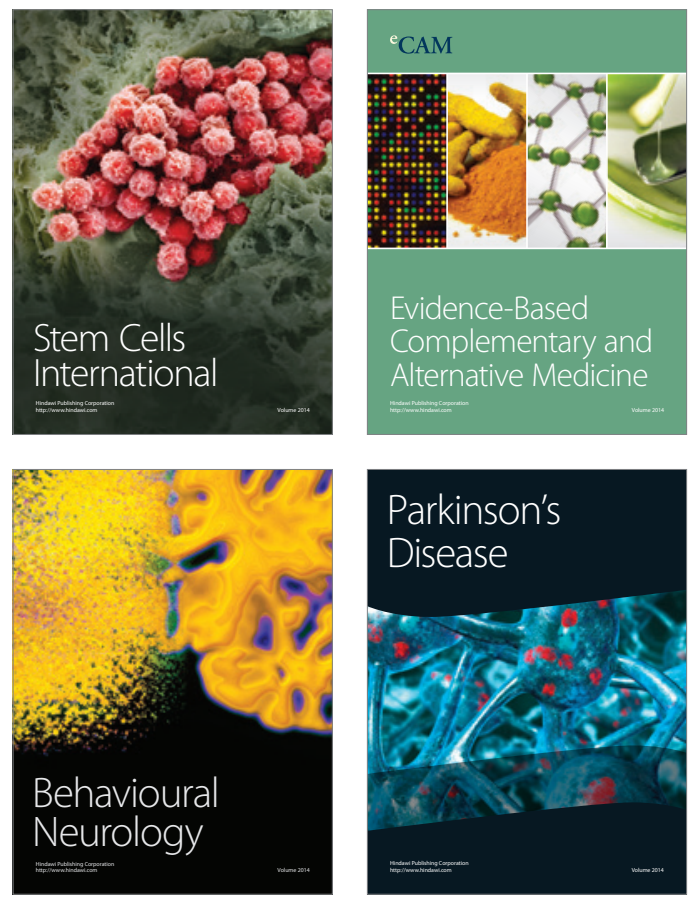
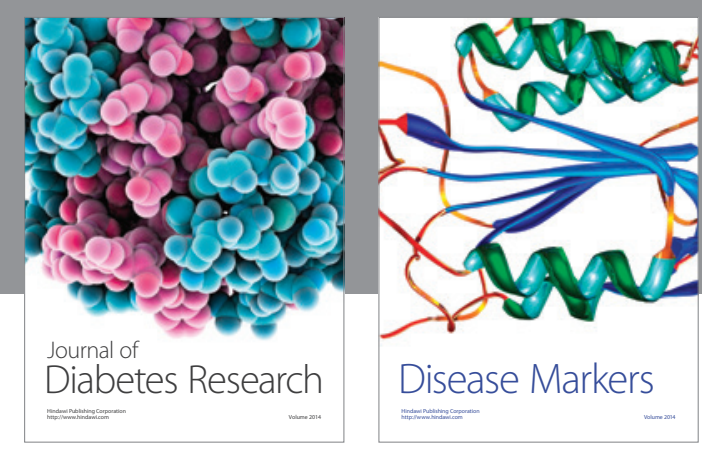

Disease Markers
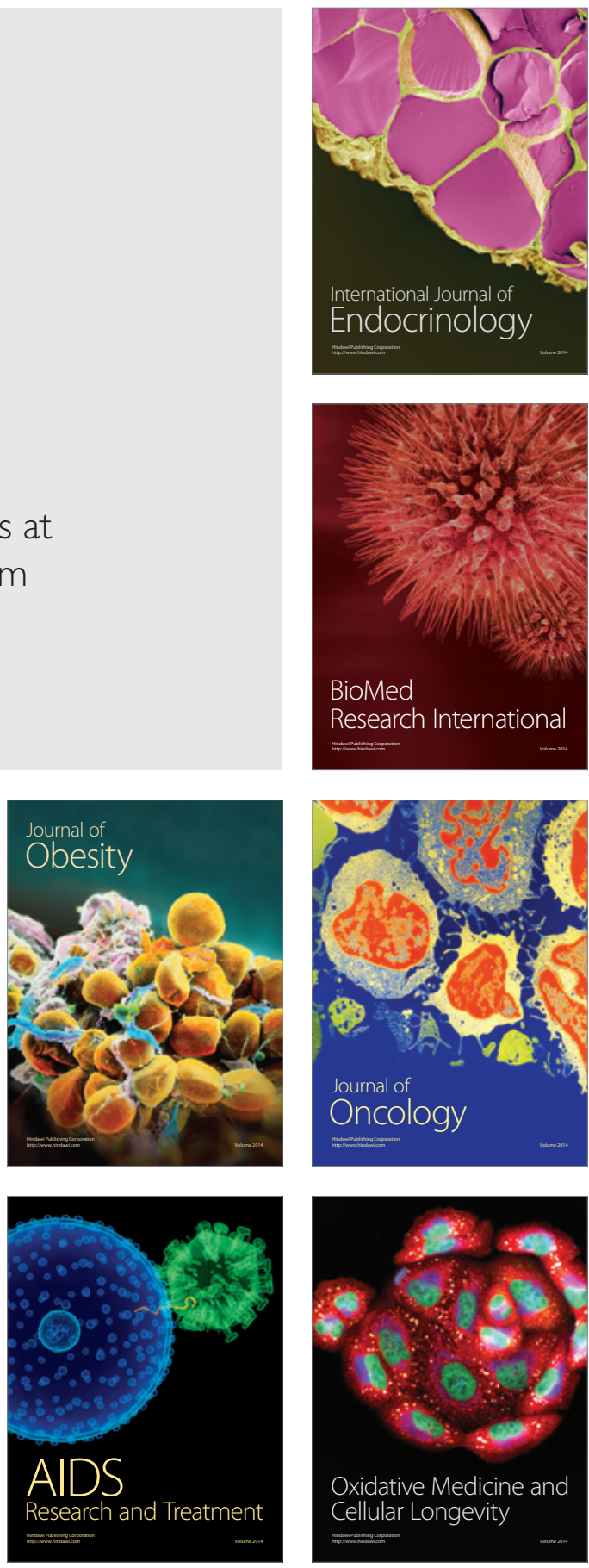